\title{
The genetic contribution of the NO system at the glutamatergic post-synapse to schizophrenia: further evidence and meta-analysis
}

\author{
H. Weber ${ }^{1,2}$, D. Klamer ${ }^{3}$, F. Freudenberg ${ }^{1}$, S. Kittel-Schneider ${ }^{1}$, O. Rivero ${ }^{1,4}$, C.-J. Scholz ${ }^{2}$, J.
} Volkert $^{1}$, J. Kopf ${ }^{1}$, J. Heupel ${ }^{1}$, S. Herterich ${ }^{5}$, R. Adolfsson ${ }^{6}$, A. Alttoa ${ }^{1}$, A. Post ${ }^{1}$, H. Grußendorf ${ }^{1}$, A. Kramer $^{1}$, A. Gessner ${ }^{1}$, B. Schmidt ${ }^{1}$, S. Hempel ${ }^{1}$, C.P. Jacob ${ }^{1}$, J. Sanjuán ${ }^{4}$, M.D. Moltó ${ }^{4}$, K.-P.

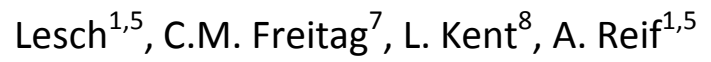

1) Department of Psychiatry, Psychosomatics and Psychotherapy, University of Würzburg, Germany

2) Microarray Core Unit, IZKF Würzburg, University Hospital of Würzburg

3) Department of Pharmacology, The Institute of Neuroscience and Physiology Sahlgrenska Academy at University of Gothenburg, Sweden

4) CIBERSAM, Universitat de Valencia, Valencia, Spain

5) Comprehensive Heart Failure Center, University of Würzburg, Würzburg, Germany

6) Department of Clinical Sciences, Psychiatry, Umeå University, Sweden

7) Department of Child and Adolescent Psychiatry, Psychosomatics, and Psychotherapy, University of Frankfurt, Germany

8) School of Medicine, University of St Andrews, Scotland, UK

Correspondence should be addressed to Andreas Reif, Department of Psychiatry, Psychosomatics and Psychotherapy, University of Würzburg, Füchsleinstr. 15, D-97080 Würzburg, Germany; Tel.: +49 931201 76402; fax.: +49 931201 77220; eMail: reif_a@klinik.uni-wuerzburg.de

Running title: NOS-I interactions at the glutamatergic post-synapse in schizophrenia Number of words in the abstract / main text: 250 / 5827 
Keywords: glutamate, nitric oxide, association, schizophrenia, posy-synapse, prefrontal cortex

\section{Abstract}

NO is a pleiotropic signaling molecule and has an important role for cognition and emotion. In the brain, NO is produced by neuronal nitric oxide synthase (NOS-I, encoded by NOS1) coupled to the NMDA receptor via PDZ interactions; this protein-protein interaction is disrupted upon binding of NOS1 adaptor protein (encoded by NOS1AP) to NOS-I. As both NOS1 and NOS1AP were associated with schizophrenia, we here investigated these genes in greater detail by genotyping new samples and conducting a meta-analysis of our own and published data. In doing so, we confirmed association of both genes with schizophrenia and found evidence for their interaction in increasing risk towards disease. Our strongest finding was the NOS1 promoter SNP rs41279104, yielding an odds ratios of 1.29 in the metaanalysis. As findings from heterologous cell systems have suggested that the risk allele decreases gene expression, we studied the effect of the variant on NOS1 expression in human post-mortem brain samples and found that the risk allele significantly decreases expression of NOS1 in the prefrontal cortex. Bioinformatic analyses suggest that this might be due the replacement of six transcription factor binding sites by two new binding sites as a consequence of proxy SNPs. Taken together, our data argue that genetic variance in NOS1 resulting in lower prefrontal brain expression of this gene contributes to schizophrenia liability, and that NOS1 interacts with NOS1AP in doing so. The NOS1-NOS1AP PDZ interface may thus well constitute a novel target for small molecules in at least some forms of schizophrenia.

\section{Introduction}

Nitric oxide (NO) is a gaseous messenger with atypical properties, acting in a pleiotropic manner by guanylyl cyclase activation and also direct nitrosylation of target proteins including CREB and thereby genomic effector mechanisms. In the brain, NO is produced by the neuronal isoform of nitric oxide synthase, NOS-I, which is encoded by the NOS1 gene located on chromosome 12q24.2-.3. Approximately one percent of all neurons express NOS-I, with almost every neuron in the brain receiving input from a NOS-I positive 
cell. However, the highest levels of NOS-I can be found in the cerebellum, cortex, basal ganglia, hypothalamus, and hippocampus. NOS-I occurs in various neuronal subtypes. Its most prominent functional interaction partner in excitatory neurons, e.g. in the cortex and the hippocampus, is the glutamatergic NMDA receptor. NOS-I is activated by calcium influx through the NMDA receptor and coupled to the site of action via the postsynaptic density, a protein scaffold comprising inter alia of the proteins PSD-93/-95, SHANK, and DLGAP. The socalled NOS1 adaptor protein NOS1AP (previously termed CAPON, carboxy terminal PDZ domain ligand of neuronal NO synthase) competes with PSD-93/-95 for NOS-I binding and has both a PDZ as well as an N-terminal phosphotyrosine binding (PTB) domain which allows it to connect NOS-I to synapsin, forming a ternary NOS-I - NOS1AP - synapsin complex (Jaffrey et al., 2002). Also, the NOS-I - NOS1AP complex can bind to RASD1 (also known as DEXRAS1) (Fang et al., 2000), which belongs to the superfamily of small GTPases and itself is activated by NO (Fang et al., 2000; Jaffrey et al., 2002). This is accomplished upon NOS1AP binding, resulting in S-nitrosylation of a cysteine residue. Another protein that interacts with NOS-I at this site is DYNLL1 (dynein, light chain, LC8-type 1), previously termed PIN (protein inhibitor of NOS-I), although specificity of this interaction and its mechanism were later questioned. Rather, it might function as part of the neuronal machinery serving the axonal transport of NOS-I, as it was shown to be part of the microtubule-associated motor protein dynein complexes and hence termed dynein light chain of $8 \mathrm{kDa}$ (LC8, DLC1). It is thought to link the dynein complex to cargo molecules including NOS-I (Rodriguez-Crespo et al., 2001), DLGAP1, GluN3A and PSD-95 (Navarro-Lerida et al., 2004) supporting the notion that DYNLL1 serves as a transport adaptor vehicle for proteins which constitute the glutamatergic postsynaptic complex. This is underscored by data showing that DYNLL1 is also part of the above mentioned NMDA - PSD-95 - NOS-I - DLGAP1 complex, probably trafficking this complex along microtubules and actin cytoskeleton (Haraguchi et al., 2000).

Both NOS-I as well as NOS1AP have repeatedly been suggested to be involved in the pathogenesis of schizophrenia which relates to the "glutamatergic" theory of schizophrenia and the role of NO in mediating NMDA receptor-mediated signaling. While there are numerous studies on animal models or post-mortem findings, reviewed elsewhere (NOS: (Bernstein et al., 2011); NOS1AP: (Brzustowicz, 2008)), the genetic data shall be summarized here in brief as both the NOS1 and the NOS1AP genes have been described as functional candidates for schizophrenia. Regarding NOS1, the majority of functional candidate gene 
studies yielded positive results, although the ethnicity of the investigated samples as well as the tested SNPs were quite heterogeneous. Only one study (Fallin et al., 2005), conducted in Ashkenazi Jews, employed a family-based design and yielding positive results. The first casecontrol study was published in 2002 and tested a potentially functional SNP in the 3'UTR in a sample of 215 Japanese schizophrenic patients (Shinkai et al., 2002), also with positive outcome. Subsequently, our group conducted a mutation analysis, qRT PCR and haplotype analysis in Caucasian patients suffering from schizophrenia arguing that a functional promoter SNP (rs41279104), resulting in decreased expression of a reporter gene in cell culture experiments (Saur et al., 2004), is associated with disease (Reif et al., 2006a). Since then, six more case-control association studies on schizophrenia and NOS1 were published in total (Cui et al., 2010; Nicodemus et al., 2010; Okumura et al., 2009; Riley et al., 2010; Tang et al., 2008; Wang et al., 2012). Four of those came from Asian populations (two Chinese (Tang et al., 2008) and two Japanese (Cui et al., 2010; Okumura et al., 2009)), with mixed results: while Cui and associates replicated the positive finding on rs41279104 (and also provided evidence for reduced NOS-I expression on the protein level in BA9 - part of the dorsolateral prefrontal cortex - for risk allele carriers), Okumura could not, although two other NOS1 SNPs were significant (but did not survive correction for multiple testing). The same was true for the study by Wang (Wang et al., 2012) in China, where a SNP in intron 2 of NOS1 was only nominally significant. In contrast, the other study from China (Tang et al., 2008) found significant evidence for an association of NOS1 (5'UTR and intron 2) with schizophrenia as well. One Irish population did not provide evidence for an association of NOS1 with schizophrenia, although only 4 SNPs were tested and did not include the previously significant rs41279104 (Nicodemus et al., 2010). Taken together, these association studies rather argue for an association of the $5^{\prime}$ end of NOS1 - especially the promoter region - with schizophrenia. Not surprisingly, a small Chinese study $(n=198)$ on a CA-dinucleotide repeat in the 3'UTR of the gene yielded negative results (Liou et al., 2002).

However, NOS1 is not only a functional candidate gene, but also a positional candidate gene as the NOS1 locus is a hot spot for schizophrenia in linkage analyses (an overview can be gathered from Fig. 1 in (Reif et al., 2006)). Yet not only linkage studies, but also genome-wide association studies (GWAS) have suggested NOS1 as a schizophrenia risk gene; with rs6490121 located in intron 10 of NOS1 yielding a p-value of $9.82 \times 10^{-6}$ in the study by O'Donovan and colleagues (O'Donovan et al., 2008), thus being the third best hit of 
the GWAS. A follow-up of this SNP in an Irish sample of 1,021 cases did not yield positive results (Riley et al., 2010), however.

The most promising association findings were followed up in endophenotype experiments. The functional promoter SNP rs41279104 was tested in studies using eventrelated potentials and functional near-infrared spectroscopy (Reif et al., 2006; Reif et al., 2011), providing evidence for a prefrontal deficit in risk allele carriers. In addition, Kawohl and associates (Kawohl et al., 2008) demonstrated that rs41279104 risk allele carriers had decreased loudness dependence of auditory evoked potentials, which is a functional marker of serotonergic transmission, arguing for a connection between the NO and serotonin systems as also shown on the protein and the neuronal network (Kiss and Vizi, 2001) level. Also, the GWAS risk SNP rs6490121 was shown to be functional in respect to general intelligence, working memory and visual sensory processing as measured by the electroencephalogram event-related P1 response (Donohoe et al., 2009; O'Donoghue et al., 2012). Most of these effects could also be observed in healthy controls, and not only patients. Also, healthy risk allele carriers had a reduction in ventromedial prefrontal grey matter volume and altered activation of this and other structures during working memory tasks (Rose et al., 2012).

In addition to NOS1, the NOS1AP gene has consistently been suggested to be associated with schizophrenia. As a finding from linkage studies on Canadian families (having Celtic or German background), suggesting the NOS1AP locus chromosome 1q22 as a linkage hot spot, this gene came into focus in psychosis research as fine-mapping could narrow the critical region to this gene (Brzustowicz et al., 2004). In the following years, this group has provided further evidence that NOS1AP is implicated in schizophrenia pathogenesis, stemming from family-based genetic studies and suggesting a functional variant (Wratten et al., 2009), although another group examining a UK sample argued that rather the neighboring gene UHMK1 underlies the linkage peak (Puri et al., 2007; Puri et al., 2006). Following up the studies of Brzustowicz and colleagues, both positive (Kremeyer et al., 2009; Miranda et al., 2006; Zheng et al., 2005) as well as negative (Fang et al., 2008; Nicodemus et al., 2010; Nicodemus et al., 2008) family-based and case-control studies were published. In addition, a mutation analysis suggested that rare coding variants in NOS1AP underlie obsessive-compulsive disorder and autism (Delorme et al., 2010). Furthermore, NOS1AP was 
suggested to play a role in antipsychotic-mediated $\mathrm{QT}_{\mathrm{c}}$ prolongation (Aberg et al., 2010) which is not surprising given its highly significant influence on the $Q T_{c}$ interval.

Due to these repeatedly described and promising associations of both NOS1 and NOS1AP (as well as three other genes coding for components of the glutamatergic synapse which interact with NOS-I in a protein-protein manner, namely DYNLL1, RASD1 and SYN2) with schizophrenia, we here tested in three samples whether we can confirm these findings and whether NOS1 and NOS1AP interact in an epistatic manner, which is expected due to their physical interaction. We also aimed to back up this data by meta-analytic approaches as well as bioinformatic analysis, and finally we attempted to replicate the functionality of NOS1 rs41279104 in human post-mortem brain tissue.

\section{Experimental Procedures}

\section{Genotyped samples}

We here extended a previously described sample (Reif et al., 2006) by genotyping more markers and adding a further 75 patients suffering from schizophrenia. In brief, a total of 270 unrelated patients (thereof $54 \%$ males; mean age $41 \pm 13$ years) from the Lower Franconia area in Germany participated, which were ascertained as inpatients at the Department of Psychiatry and Psychotherapy, University of Würzburg. None of the subjects remitted completely during the course of the disease and thus the sample consists entirely of patients suffering from chronic schizophrenia, i.e. it is selected for severe cases; diagnostic evaluation was made by at least two experienced psychiatrists. The control sample consisted of 720 individuals (thereof $52 \%$ males; mean age $33 \pm 11$ years), all healthy blood donors, hospital staff and volunteers stemming from the same catchment area as the patient group. A further 101 patients with schizophrenia were recruited from care centers in Umeå, Northern Sweden. All patients had at least two discharge diagnoses of schizophrenia as well as a life-time diagnosis of schizophrenia. Final diagnosis was determined by the consensus of two research psychiatrists, and only patients for whom full consensus was reached were included. Mean age of patients at the time of DNA sampling was 50 years. Control subjects ( $n=168$, mean age 59 years) were recruited from a random population prospective longitudinal study in Umeå, and none of the controls had a life-time diagnoses of schizophrenia or any other psychotic disorder. The sex ratio was similar in the two samples: the schizophrenic patients consisted of $52 \%$ males, and the control subjects of $45 \%$ 
males. Finally, 270 unrelated psychiatric patients (thereof 84 females) from Spain were included (mean age 39 \pm 11 years). Patients came from the psychiatric in-patient and outpatient units of the Mental Health Service 4 of the Clinical Hospital, University of Valencia, Spain. The retrospective clinical data collected from each patient were compared with the information provided from previous clinical reports and family members. Diagnoses were confirmed by a consensus meeting with the treating psychiatrist and one of the psychiatrists of the research group. Patients also had a minimum one-year evolution of the illness and were on antipsychotic treatment at evaluation time. The control group consisted of 360 healthy unrelated subjects of Spanish origin (thereof 124 females) with no history or familiar background of mental disorders (mean age $37 \pm 15$ years).

All of the patients suffered from schizophrenic disorders according to ICD-10 (Germany) or DSM-IV (Spain, Sweden) criteria. None of the subjects showed significant neurological comorbidity, epilepsy, mental retardation, or other somatic disorders suggesting organic psychiatric disorder. Patients with substance-induced psychotic episodes were excluded from the study as well. Both patients as well as controls were of Caucasian ethnicity. Only patients and volunteers who gave written informed consent after oral as well as written explanation about scope and aim of the investigation were enrolled in the study. All studies complied with the Declaration of Helsinki and were approved by the respective local ethical committees; informed consent was obtained from all participating subjects.

\section{Genotyping and SNP selection}

SNPS in the NOS1AP and NOS1 regions have previously been examined in casecontrol studies of schizophrenia \{Brzustowicz, 2004 \#252; Cui, 2010 \#715; Nicodemus, 2010 \#747; Okumura, 2009 \#749; Puri, 2006 \#755; Tang, 2008 \#676; Zheng, 2005 \#299\}. To enable meta-analysis, we have selected 13 NOS1AP SNPs (rs1572495, rs1538018, rs945713, rs1415263, rs4306106, rs3924139, rs4145621, rs1508263, rs3751284, rs7521206, rs905721, rs348624, rs1964052) and 8 NOS1 SNPs (rs3782206, rs3837437, rs499776, rs3782219, rs3782221, rs1879417, rs4767540, rs41279104) from previously published studies for further genotyping. Furthermore, SYN2 SNPS have previously been analyzed in a familybased setting in schizophrenia \{Saviouk, 2007 \#784\}; we have selected seven polymorphisms (rs598747, rs598704, rs308969, rs931676, rs3817004, ss35528972, rs3755724) for genotyping from this study, however, we did not carry out a meta-analysis due to the 
different study types. For RASD1 and DYNLL1, no publications reported on an associations with schizophrenia; we therefore selected a set of eight representative SNPS (RASD1: rs4924755, rs711352, rs2232841, rs2232838; DYNLL1: rs12857, rs3916065, rs787828, rs9788155) capturing the common allelic variation in these genes including the $5 \mathrm{~kb}$ upstream and $3 \mathrm{~kb}$ downstream regions with minimal genotyping effort. For SNP selection, we used the Tagger function implemented in Haploview 4.2 using HapMap CEU as reference population. Together, this resulted in 36 selected SNPs. Genomic DNA of all participants was extracted from venous blood by the standard methods. Subsequent SNP genotyping was performed with Sequenom's MassArray ${ }^{\circledR}$ system using the iPlex ${ }^{\circledR}$ chemistry following the MassArray ${ }^{\circledR}$ iPlex $^{\circledR}$ standard operation procedure. Primer sequences can be found in Supplementary Table 1.

\section{NOS1 mRNA quantification}

For quantification of total NOS1 RNA expression in human brain, a sample of human post-mortem brains, with post-mortem intervals (PMI) from $28 \mathrm{~h}$ up to $111 \mathrm{~h}$ (mean PMI $54.84 \pm 16.63$ ) was obtained from the Medical Research Council (MRC) Sudden Death Brain and Tissue Bank, Edinburgh. From 76 deceased individuals, aged between 16 and 74 ( $N=76$; female $=18$, male $=58 ;$ mean age $48.55 \pm 12.79)$, DNA and RNA from three brain regions (amygdala, forebrain and midbrain) were isolated, using the MELT ${ }^{\mathrm{TM}}$ Total Nucleic Acid Isolation System (Applied Biosystem, AM Foster City, 1983) and stored at $-80^{\circ} \mathrm{C}$ until use. RNA quality, measured with a Bioanalyzer (Agilent), revealed RNA integrity numbers (RIN) ranging from 1.5-2.0. Total RNA from forebrain, midbrain and the amygdala of human post-

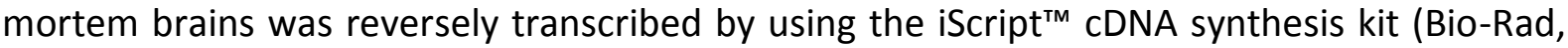
München, Germany) on $1 \mu \mathrm{g}$ total RNA of each sample. cDNA was quantified in triplicates on a Bio-Rad CFX384 real-time PCR detection system, by applying the $\mathrm{iQ}^{\mathrm{TM}}$ SYBR green supermix from Bio-Rad and NOS1-specific QuantiTect Primer (QT00043372) from Qiagen in a $10 \mu \mathrm{l}$ reaction volume. $\mathrm{PCR}$ conditions were $5 \mathrm{~min}$ at $95^{\circ} \mathrm{C}, 40$ cycles of $10 \mathrm{~s}$ at $95^{\circ} \mathrm{C}, 30 \mathrm{~s}$ at $60^{\circ} \mathrm{C}$, followed by a melting curve analysis with a gradient of $65^{\circ} \mathrm{C}$ to $95^{\circ} \mathrm{C}$ of $0.5^{\circ} \mathrm{C}$ per $5 \mathrm{~s}$. Raw NOS1 expression data were normalized by mean efficiencies obtained from LinRegPCR and normalization factors based on the three (of six investigated) most stable housekeeping genes (GAPDH, TBP, SDHA), defined by the geNorm software. To investigate the influence of rs41279104 on gene expression, we carried out ANOVAs and post-hoc t-tests on normalized 
logarithmized NOS1 expression values in genotypic and dominant models. Allele-specific changes of gene expression were examined with linear regression.

\section{Statistical Analysis}

Statistical analysis of genotype data was performed with PLINK version 1.07 and $R$ version 2.10. Quality control required polymorphic variants with a minor allele frequency (MAF) above $1 \%$, a call rate (CR) above $90 \%$ and that overall genotype frequencies did not deviate from Hardy-Weinberg equilibrium (HWE; $\chi^{2}$ HWE $p$-value $\geq 0.05$ ); thirty variants complied with these inclusion criteria. In all three samples (i.e., German, Swedish and Spanish), rs3837437 yielded a MAF below 0.01; rs2232841, rs2232838, rs3916065, rs4145621, rs931676 did not reach the CR threshold and were thus excluded from further analysis.

Single-marker associations were calculated by comparison of allele and genotype counts using Fisher's exact tests. Calculations were performed in each sample separately to account for ethnic discrepancies; for joint analyses, samples were subjected to meta-analysis (see below). For multi-marker association, haplotype blocks were defined according to the solid spine method; inferred haplotype counts in groups were compared with 1-degree-offreedom $\chi^{2}$ tests. P-values from single marker and haplotype analyses were separately adjusted for the number of tests performed in each sample using the conservative Bonferroni correction. In the combined analysis of all three samples, we achieve a power of $66 \%$ and $62 \%$ to detect nominal significant SNPs and haplotypes, respectively, conveying a relative risk of 1.4 to develop schizophrenic disorder assuming a co-dominant model and a MAF of 0.05 (Power for Genetic Association version 2.0).

Meta-analysis

To obtain maximal information regarding the NOS1 and NOS1AP variants tested in the present study, we performed a meta-analysis of the data (significant SNPs only) presented here together with all previous case-control genotyping efforts. To this end, a Pub Med search was carried out using the keywords "(NOS1AP OR CAPON) AND schizophrenia" as well as "NOS1 AND schizophrenia", to identify all genetic studies on NOS1AP ( $\mathrm{n}=24$ retrieved studies) or NOS1 ( $\mathrm{n}=42$ retrieved) and schizophrenic disorders. Titles and abstracts were scrutinized to exclude non-genetic studies, reducing the number of included studies to 
15 for NOS1AP and 15 for NOS1. Of those, 9 studies on NOS1AP (Brzustowicz et al., 2004; Costain et al., 2010; Fang et al., 2008; Greenwood et al., 2011; Husted et al., 2010; Kremeyer et al., 2009; Miranda et al., 2006; Nicodemus et al., 2008; Wratten et al., 2009) and one on NOS1 (Fallin et al., 2005), presented family-based, but not case-control data and were therefore not integrated in the meta-analysis for methodological reasons. The remaining studies on NOS1AP ( $n=6$; (Aberg et al., 2010; Delorme et al., 2010; Nicodemus et al., 2010; Puri et al., 2007; Puri et al., 2006; Zheng et al., 2005)) and NOS1 ( $n=14$; (Cui et al., 2010; Donohoe et al., 2009; Kawohl et al., 2008; Nicodemus et al., 2010; O'Donoghue et al., 2012; Okumura et al., 2009; Reif et al., 2006; Reif et al., 2011; Riley et al., 2010; Rose et al., 2012; Shinkai et al., 2002; Silberberg et al., 2010; Tang et al., 2008; Wang et al., 2012)) reported on case-control association data and were scrutinized in greater detailed. For NOS1AP, two and for NOS1, 11 further studies had to be excluded from meta-analysis for the following reasons. For the NOS1AP gene: (Aberg et al., 2010) reported on cases only, while (Puri et al., 2007) investigated SNPs that were not included in our genotyping battery. For the NOS1 gene: (Kawohl et al., 2008; O'Donoghue et al., 2012; Rose et al., 2012) analysed exclusively healthy participants. (Donohoe et al., 2009; Nicodemus et al., 2010; Riley et al., 2010) and (Shinkai et al., 2002) only presented data on SNPs which have not been genotyped for the present study; no SNP data could be obtained from the study of (Wang et al., 2012); and the study by (Silberberg et al., 2010) was excluded because of the rather small sample size $(n=26)$ precluding meaningful interpretation of the data. Finally, (Reif et al., 2011) and (Reif et al., 2006), were excluded because the case samples of both studies overlapped with the sample described here (while the control sample was extended more than two-fold). Therefore, four studies on NOS1AP $\left(\mathrm{n}_{\max }{ }^{\text {cases }}=2406\right)$ and three studies on NOS1 $\left(n_{\max }{ }^{\text {cases }}=2006\right)$ were meta-analytically treated together with the data presented in this report yielding a sample power of $99 \%$ for NOS1AP and $98 \%$ for NOS1 to detect SNPS associations, based on a relative risk of 1.4 and a MAF of 0.05 .

The calculations for meta-analysis were performed using $\mathrm{R}$ version 2.10 along with the package metaphor version 0.5-7 using the "rma" command. For meta-analysis, we calculated odds ratios (ORs) as a measure for effect size and applied the Q-statistic to assess heterogeneity therein. Inconsistency across studies was quantified with the $1^{\wedge} 2$ metric $\left(I^{\wedge} 2=Q-d f / Q\right)$. The joint $O R$ was determined as the weighted average of effect sizes entering the meta-analysis. When no heterogeneity was detected in the effect sizes, we applied fixed- 
effects models, where the weights correspond to the inversed variances of the study ORs. In the presence of significant $(p<0.05)$ heterogeneity, we applied random-effects models. Here, weights are initially calculated as in the fixed-effects model, but are then down-weighted by the degree of variance of effect sizes. Visual inspection of Funnel plots (Supplementary Figure 1) did not argue for the presence of publication bias.

\section{Interaction analysis}

Interaction analyses were calculated with PLINK version 1.07. SNPs with Bonferroniresistant association and/or $\mathrm{p}<0.05$ in the meta-analysis (see below) were subjected to pairwise interaction analysis, examining the genetic effect of one SNP in dependence of the genotype of the other SNP. The search for such epistatic effects was performed in two modes, namely in the whole case-control sample with the command "fast-epistasis" and in the case-only study subset by use of the additional command "case-only". Calculations were performed separately in each study sample as well as in the combined sample to increase power.

\section{Bioinformatic analysis}

Analyses of SNPs were performed with tools that are contained in the GenEpi toolbox (http://genepi_toolbox.i-med.ac.at/). Annotation of SNPs in linkage disequilibrium (LD) with associated SNPs in a distance of $500 \mathrm{~kb}$ was retrieved from the SNAP website version 2.2. Differential transcription factor binding site (TFBS) predictions were made using the webbased tool MatInspector version 2.1. To indicate a SNP's possible influence on splice junctions such as predictions of splice sites as well as binding sites for splicing regulatory elements (SREs, including Intronic Splicing Enhancer (IES) and Intronic Splicing Silencer (ISS)), the Human Splicing Finder software (HSF) version 2.4.1 was used.

\section{Results}

Single marker analysis

We calculated case-control single marker analyses for each of the three samples separately due to their different geographic origin. Genotypic, allelic as well as dominant models were used (Table 1). Of the 12 SNPs in NOS1AP, six were nominally associated in at least one of the samples, with rs945713 surviving Bonferroni correction in the German 
sample. In the Swedish sample, this SNP displayed a trend towards association $(p=0.064)$. Three of the seven examined NOS1 SNPs were nominally associated in at least one sample; rs499776 survived Bonferroni correction in the Swedish sample and was nominally associated in the two other samples. No SNP associations were observed in SYN2, DYNLL1 and RASD1.

Haplotype analysis

LD plots of the analyzed NOS1AP and NOS1 regions are displayed in Figure 1. In the haplotype analysis, we found two associated haplotypes in NOS1AP's block 1 in the Swedish sample (Table 2) containing SNPs that all were significant in the single marker analysis in this sample. Furthermore, in the German sample, a NOS1 haplotype containing rs4767540 and rs41279104 was nominally significant $(p=0.028)$, although not on the Bonferroni-adjusted level.

Meta-analysis

All NOS1AP (Table 3) and NOS1 (Table 4, Figure 2) SNPs genotyped in the present study were subjected to a meta-analysis, thereby also incorporating results from previously published studies. The maximum number of investigated patients was 2,466 for NOS1AP and 2,006 for NOS1, respectively. Six NOS1AP SNPs displayed significantly heterogeneous genetic effects, but no significant pooled effect size was determined with random effects models (Tables 3 and 4). In contrast, effect sizes of all examined NOS1 SNPs were homogeneous; three thereof conveyed a significant pooled genetic effect (Table 4, Figure 2): rs3782206, rs499776 and rs41279104, with the latter yielding the strongest signal conveying odds ratios of 1.29 (dominant model) and 1.25 (allelic model), respectively.

Interaction analysis

Epistatic effects were tested in pairwise combinations of SNPs rs945713 and rs499776 as well as rs3782206 and rs41279104, of which meta-analytic treatment predicted significant genetic effect sizes (see above). Neither the separate nor the combined casecontrol samples revealed a significant interaction. However, when considering cases only, a significant interaction between rs945713 and rs41279104 was found in the German $(p=0.004)$ and the combined sample $(p=0.012)$. 
Allele-specific mRNA quantification in human post-mortem prefrontal cortices revealed a significant linear reduction (beta=-0.087) of NOS1 expression values per minor/risk T allele of rs41279104. Differential expression by genotype group showed significant association in the prefrontal cortex (ANOVA $p=0.036$, post hoc t-test $p=0.012$ ). NOS1 expression in the amygdala or the midbrain was not found to be influenced by rs41279104 (data not shown).

Bioinformatic analysis of rs945713, rs3782206, rs499776 and rs41279104

For functional prediction of rs945713, rs3782206, rs499776 and rs41279104, high LD proxies $\left(r^{2} \geq 0.9\right.$ and $\left.D^{\prime}=1\right)$ were searched within a distance of $500 \mathrm{~kb}$ (Suppl. Table 2). This search resulted for the NOS1AP variant rs945713 in six high LD proxies, all located in the second intron of the gene. The three NOS1 SNPs rs41279104, rs499776 and rs3782206 had altogether 33 proxies of which six were located in the promoter region, four in the first and 23 in the second intron of NOS1. For the promoter SNP rs41279104, which was found to be most strongly associated with schizophrenia, no clear function was predicted, but the minor alleles of its four proxies rs900622, rs12316771, rs34731287 and rs12312120 replace six transcription factor binding sites (TFBS) for HOXC9, MSX1, ELF5, DLX1, SPZ1 and MAZR by two new binding sites for E2F and HMX3. As all predicted TFBS are expressed in the nervous system, we predict rs41279104 together with its four promoter proxies to have an effect on NOS1 expression, which is in line with the significant differential mRNA level in forebrain (see previous section).

Moreover, we observed differences in counts of predicted splicing regulatory elements between major and minor alleles of associated intronic SNPs and their proxies. Specifically, the risk (minor) allele of the NOS1AP variant rs945713 replaces binding sites for two splicing enhancers (SE) by one splicing inhibitor (SI). Furthermore, the NOS1 associated SNP rs3782206 and its proxies create three SI and 11 SE binding sites, but erase 6 SI and 16 SE binding sites in the presence of the minor risk allele (suppl. Table 1). Finally, the protective minor allele of rs499776 along with its two proxies rs570234 and rs1681506 decrease the predisposition towards schizophrenia by deletion of three binding sites for SES (see Suppl. Table 2), which may repress alternative splicing of NOS1 transcripts. 


\section{Discussion}

\section{Molecular effects of risk alleles}

By investigating three discovery samples from Germany, Sweden and Spain, followed by meta-analysis of these and published data, we provide evidence that variants of genes coding for components of the NO system at the glutamatergic post-synapse interact to increase the risk towards schizophrenia. While neither RASD1, DYNLL1 (which have not yet been specifically tested before) nor SYN2 (which had some prior evidence; (Saviouk et al., 2007)) gave a significant signal, SNPs in NOS1AP and NOS1 did; both genes in the present case-control studies and the latter also in the meta-analysis. These SNPs have been previously suggested to contribute to schizophrenia liability, and most interestingly, they also interacted in increasing disease risk. Odds ratios were in the expected range for common variants, although the NOS1 promoter polymorphism rs41279104 conveyed a relatively high risk with an $O R=1.3$. Most interestingly, following initial studies arguing for an effect of this SNP on reporter gene expression in heterologous cell systems, we could extend this data here by showing that the risk allele resulted in lower NOS1 expression in the prefrontal cortex which is in line with data showing reduced NOS-I immunohistochemical staining in the prefrontal cortex in risk allele carriers (Cui et al., 2010). To clarify molecular function of rs41279104 and six high LD proxy SNPs on NOS1 expression in greater detail, we used several in silico approaches which revealed that the SNPs' minor alleles replace putative binding sites for transcription factors that are known to be expressed in the prefrontal cortex; this provides a possible mechanism how rs41279104 by means of its proxies may influence NOS1 expression.

In contrast to our results, a study by Silberberg et al. (2010) did not detect any changes in NOS1 expression in rs41279104 carriers. Importantly, in the study by Silberberg et al. (2010) samples from both healthy and schizophrenic subjects were used, with increased NOS1 expression in patients with schizophrenia, regardless of genotype. In contrast, samples analyzed in our study were only obtained from healthy subjects. Therefore, it is possible that in the Silberberg et al. (2010) study increased NOS1 expression in schizophrenic patients is masking a possible reduction in NOS1 expression caused by rs41279104. Alternatively, this might be due to a mere power problem, inherent to this kind of studies where only a few risk allele carriers can be tested and overall sample size is 
limited. Moreover, this could be a brain region-specific effect, or different LD structure in the tested population. Nevertheless we are confident that we are indeed picking up true molecular consequences of rs41279104 at least in Caucasians.

Interestingly, a number of studies have suggested that NO plays an important role in the biochemical and behavioral effects of the psychotomimetic NMDA-receptor antagonist phencyclidine (PCP) (Palsson et al., 2010), and a recent finding demonstrates that prefrontal NO/sGC signaling is important for the effects of PCP (Fejgin et al., 2008). However, preclinical and clinical data underscores that both an abnormal increase and a decrease in NO signaling can underlie schizophrenia-like deficits. Taken together, the present and previous findings indicate a dysregulated NO system as part of the pathophysiology of schizophrenia. Hence, pharmacological manipulation of NO activity may be a fruitful approach when trying to alleviate cognitive dysfunctions in schizophrenia.

NOS-I - NOS1AP interaction as a molecular mechanism in schizophrenia

NOS1 and NOS1AP tightly interact on the protein level and both proteins have repeatedly been associated with schizophrenia not only on the genetic level, as outlined above, but also coming from other lines of research. The NOS I protein carries an aminoterminal PSD 95/Discs large/Zonula occludens 1 (PDZ)-domain followed by a $\beta$ finger encoding a PDZ-motif (-ETTF-). The PDZ-motif of NOS I interacts with the PDZ2 domain of PSD 95/ 93, thereby anchoring NOS I to the postsynaptic density and allowing proximity of NOS-I to NMDA receptors. This allows activity-dependent NO production by NOS-I by Calcium-influx through NMDA receptors. The PDZ-domain of NOS-I directly interacts with NOS1AP (Jaffrey et al., 1998), which alters the subcellular localization of NOS-I away from the post synaptic density, by binding to RASD1 (Fang et al., 2000) or Synapsin 1 (Jaffrey et al., 2002). The binding of NOS1AP to NOS-I directly competes with the interaction between NOSI and PSD-95/-93, and overexpression of NOS1AP was shown to reduce the interaction between NOS-I and NOS1AP (Jaffrey et al., 1998). Blocking the PDZ-domain of NOS-I with small molecule inhibitors has been suggested as a possible therapeutic approach in the treatment of depression, a hypothesis that is supported by preclinical evidence (Doucet et al., 2013). Since we show that expression levels of NOS-I are reduced in rs41279104 risk allele carriers, and since elevated expression of NOS1AP interfering with post-synaptic targeting of NOS-I (Jaffrey et al., 2002; Jaffrey et al., 1998) is elevated in schizophrenic 
patients (Xu et al., 2005), a comparable approach (i.e., blocking NOS-I - NOS1AP interaction with small molecules) might provide a feasible strategy for treatment at least in patients carrying this risk allele. In this context, it is also interesting to note that another SNP that was associated with schizophrenia in a family-based study (and therefore not included in our meta-analysis) produced elevated NOS1AP promoter activity in human cell lines (Wratten et al., 2009).

\section{Human functional consequences of comprised prefrontal NOS functioning}

Being stimulated by findings in Nos1 knockout mice that feature cognitive deficits (Zoubovsky et al., 2011), studies on the differential influence of NOS1 polymorphisms on human cognition provided compelling evidence for a role of this gene in prefrontal function. This was not only shown in patients, but rather also in healthy controls outlined in this section. For instance, we demonstrated (Reif et al., 2006) that the rs41279104 risk allele is associated with fewer errors and a reduced P300 latency in a continuous performance test (CPT) and argued that this polymorphism, leading to reduced NOS1 expression in the prefrontal cortex, might raise efficiency for executive functions by reducing the signal to noise ratio. This is achieved via lower NO levels, which will result in less activation of neighboring neurons (a smaller "NO cloud", see (Kiss and Vizi, 2001)). We later reported an influence of another NOS1 promoter polymorphism (NOS1 ex1f-VNTR) on the same task. Performance during the CPT was measured with EEG and the resulting No-Go centroid, associated with activation of the anterior cingulate gyrus (ACC), was localized significantly more posterior in subjects carrying the risk allele of NOS1 ex1f-VNTR, which also leads to lower NOS1 expression. This was interpreted as a diminished ACC activation in risk allele carriers leading to impaired medial prefrontal functioning. This assumption was corroborated by data showing brain differential activation in NOS1 ex1f-VNTR risk allele carriers in a working memory and a stop-signal task (Kopf et al., 2012).

Furthermore, another NOS1 polymorphism (rs6490121) was associated with working memory as homozygous carriers of the risk allele performed more poorly (Donohoe et al., 2009). This effect was also observed for verbal IQ measures. That same SNP was found to be associated with lower P1 visual evoked potentials elicited by a spatial working memory task in a high density EEG study (O'Donoghue et al., 2012). Carriers of the risk allele showed significantly lower P1 responses than non-carriers, pointing to a function of NOS1 even in 
early sensory processing. Finally, Rose and colleagues (Rose et al., 2012) used voxel based morphometry and showed that grey matter volume in the ventromedial prefrontal cortex is significantly reduced in risk allele carriers. They also conducted a spatial working memory test and demonstrated increases in the activation of fronto-parietal working memory networks and a failure to disengage regions of the default mode network for risk allele carriers. Taken together, present data strongly suggests that genetic variation in NOS1 mainly underlying reduced expression of the gene - leads to compromised cognitive functioning and differential prefrontal brain activity also in healthy individuals. This influence on neurocircuitry exerted by NOS1 might well underlie the association of this gene with schizophrenia, where cognitive deficits are amongst the core symptoms of the disease.

\section{Limitations}

A few limitations have to be considered in the interpretation of our data. First, the power of the discovery samples to detect effects was intermediate which might compromise the interaction analysis; as the meta-analytic study was well-powered, we aimed to overcome this issue. However, meta-analysis did not cover all previously significant SNPs so that further large-scale studies should incorporate a more extensive SNP panel also allowing for gene-based analyses. Ethnic differences in the investigated samples have also been taken into account, as different LD structures in different populations might obscure the linkage with "true" underlying risk variants. On the pathophysiological level, our data is at odds with three other studies arguing for unchanged (Cui et al., 2010) or even increased (Baba et al., 2004; Silberberg et al., 2010) NOS1 expression in schizophrenia. As the study by Cui and associates also found reduced NOS1 expression in risk allele carriers, one might rather assume that reduced NOS1 expression is not to be found in schizophrenia as a whole but rather there is a genetically distinct schizophrenia sub-group that is characterized by compromised NO signaling, while other sub-groups might display compensatory upregulation of NOS1. Such a genetic dissection of schizophrenia might lead to more meaningful insights into disease mechanisms than rather treating the disorder on the aggregate level which obscures biological findings.

\section{Outlook}

Taken together, from our data it appears that reduction of NOS-I expression as a consequence of genetic variation and especially in conjunction with increased NOS1AP 
expression poses a risk factor for the development of schizophrenia. Further downstream, reduction of PSD-95/-93 associated NOS-I and consequently compromised NMDA - NO signaling might be the converging mechanism underlying at least some forms of psychosis. This puts NO pathways in the glutamatergic post-synapse central to the development of this disorder and calls for innovative pharmacological targeting of this protein complex. In line with these assumptions, a recent study demonstrated that a single dose of an NO donor was able to significantly reduce schizophrenia symptoms rapidly (4h) after infusion, and that this effect was detectable for almost 4 weeks (Hallak et al., 2013). Thus, genetic data informing about reduced NOS1 expression might well provide information on which patients would best benefit from such an intervention in the sense of personalized medicine. According studies to either corroborate or reject this hypothesis might provide valuable insights in the role of NO in schizophrenia.

\section{Acknowledgements}

We are grateful to all patients for their participation in the study. We thank M. Zimmer for his kind help in operating the mass spectrometer. C. Gagel, I. Reck, N. Döring and J. Auer are credited for excellent technical assistance. HW and CJS are funded by the IZKF Würzburg. FF is funded by the Feodor-Lynen Foundation. AR and KPL are supported by the Deutsche Forschungsgemeinschaft (KFO 125 to AR and KPL, TRR 58/A1 and A5 to KPL, and TRR 58/B6 and Z2 to AR, RE1632/5-1 to AR, RTG 1256 to KPL and AR). 


\section{References}

Aberg, K., Adkins, D.E., Liu, Y., McClay, J.L., Bukszar, J., Jia, P., Zhao, Z., Perkins, D., Stroup, T.S., Lieberman, J.A., Sullivan, P.F., van den Oord, E.J., 2010. Genome-wide association study of antipsychotic-induced QTc interval prolongation. Pharmacogenomics J 12, 165-172.

Baba, H., Suzuki, T., Arai, H., Emson, P.C., 2004. Expression of nNOS and soluble guanylate cyclase in schizophrenic brain. Neuroreport 15, 677-680.

Bernstein, H.G., Keilhoff, G., Steiner, J., Dobrowolny, H., Bogerts, B., 2011. Nitric oxide and schizophrenia: present knowledge and emerging concepts of therapy. CNS Neurol Disord Drug Targets 10, 792-807.

Brzustowicz, L.M., 2008. NOS1AP in schizophrenia. Curr Psychiatry Rep 10, 158-163.

Brzustowicz, L.M., Simone, J., Mohseni, P., Hayter, J.E., Hodgkinson, K.A., Chow, E.W., Bassett, A.S., 2004. Linkage Disequilibrium Mapping of Schizophrenia Susceptibility to the CAPON Region of Chromosome 1q22. Am J Hum Genet 74, 1057-1063.

Costain, G., Ho, A., Crawley, A.P., Mikulis, D.J., Brzustowicz, L.M., Chow, E.W., Bassett, A.S., 2010. Reduced gray matter in the anterior cingulate gyrus in familial schizophrenia: $a$ preliminary report. Schizophr Res 122, 81-84.

Cui, H., Nishiguchi, N., Yanagi, M., Fukutake, M., Mouri, K., Kitamura, N., Hashimoto, T., Shirakawa, O., Hishimoto, A., 2010. A putative cis-acting polymorphism in the NOS1 gene is associated with schizophrenia and NOS1 immunoreactivity in the postmortem brain. Schizophr Res.

Delorme, R., Betancur, C., Scheid, I., Anckarsater, H., Chaste, P., Jamain, S., Schuroff, F., Nygren, G., Herbrecht, E., Dumaine, A., Mouren, M.C., Rastam, M., Leboyer, M., Gillberg, C., Bourgeron, T., 2010. Mutation screening of NOS1AP gene in a large sample of psychiatric patients and controls. BMC Med Genet 11, 108.

Donohoe, G., Walters, J., Morris, D.W., Quinn, E.M., Judge, R., Norton, N., Giegling, I., Hartmann, A.M., Moller, H.J., Muglia, P., Williams, H., Moskvina, V., Peel, R., O'Donoghue, T., Owen, M.J., O'Donovan, M.C., Gill, M., Rujescu, D., Corvin, A., 2009. Influence of NOS1 on verbal intelligence and working memory in both patients with schizophrenia and healthy control subjects. Arch Gen Psychiatry 66, 1045-1054.

Doucet, M.V., Levine, H., Dev, K.K., Harkin, A., 2013. Small-Molecule Inhibitors at the PSD95/nNOS Interface have Antidepressant-Like Properties in Mice. Neuropsychopharmacology.

Fallin, M.D., Lasseter, V.K., Avramopoulos, D., Nicodemus, K.K., Wolyniec, P.S., McGrath, J.A., Steel, G., Nestadt, G., Liang, K.Y., Huganir, R.L., Valle, D., Pulver, A.E., 2005. Bipolar I disorder and schizophrenia: a 440-single-nucleotide polymorphism screen of 64 candidate genes among Ashkenazi Jewish case-parent trios. Am J Hum Genet 77, 918-936.

Fang, C., Tang, W., Tang, R.Q., Wang, L., Zhou, G.Q., Huang, K., Li, X.W., Feng, G.Y., He, M., Du, L.Z., Zhu, S.M., Xing, Y.L., Sang, H., He, L., Shi, Y.Y., 2008. Family-based association studies of CAPON and schizophrenia in the Chinese Han population. Prog Neuropsychopharmacol Biol Psychiatry 32, 1210-1213. 
Fang, M., Jaffrey, S.R., Sawa, A., Ye, K., Luo, X., Snyder, S.H., 2000. Dexras1: a G protein specifically coupled to neuronal nitric oxide synthase via CAPON. Neuron 28, 183-193.

Fejgin, K., Palsson, E., Wass, C., Svensson, L., Klamer, D., 2008. Nitric oxide signaling in the medial prefrontal cortex is involved in the biochemical and behavioral effects of phencyclidine. Neuropsychopharmacology 33, 1874-1883.

Greenwood, T.A., Lazzeroni, L.C., Murray, S.S., Cadenhead, K.S., Calkins, M.E., Dobie, D.J., Green, M.F., Gur, R.E., Gur, R.C., Hardiman, G., Kelsoe, J.R., Leonard, S., Light, G.A., Nuechterlein, K.H., Olincy, A., Radant, A.D., Schork, N.J., Seidman, L.J., Siever, L.J., Silverman, J.M., Stone, W.S., Swerdlow, N.R., Tsuang, D.W., Tsuang, M.T., Turetsky, B.I., Freedman, R., Braff, D.L., 2011. Analysis of 94 candidate genes and 12 endophenotypes for schizophrenia from the Consortium on the Genetics of Schizophrenia. Am J Psychiatry 168, 930-946.

Hallak, J.E.C., Maia-de-Oliveira, J.P., Abrao, J., Evora, P.R., Zuardi, A.W., Crippa, J.A.S., Belmonte-de-Abreu, P., Baker, G.B., Dursun, S.M., 2013. Rapid Improvement of Acute Schizophrenia Symptoms After Intravenous Sodium Nitroprusside. JAMA Psychiatry in press.

Haraguchi, K., Satoh, K., Yanai, H., Hamada, F., Kawabuchi, M., Akiyama, T., 2000. The hDLGassociated protein DAP interacts with dynein light chain and neuronal nitric oxide synthase. Genes Cells 5, 905-911.

Husted, J.A., Ahmed, R., Chow, E.W., Brzustowicz, L.M., Bassett, A.S., 2010. Childhood trauma and genetic factors in familial schizophrenia associated with the NOS1AP gene. Schizophr Res 121, 187-192.

Jaffrey, S.R., Benfenati, F., Snowman, A.M., Czernik, A.J., Snyder, S.H., 2002. Neuronal nitricoxide synthase localization mediated by a ternary complex with synapsin and CAPON. Proc Natl Acad Sci U S A 99, 3199-3204.

Jaffrey, S.R., Snowman, A.M., Eliasson, M.J., Cohen, N.A., Snyder, S.H., 1998. CAPON: a protein associated with neuronal nitric oxide synthase that regulates its interactions with PSD95. Neuron 20, 115-124.

Kawohl, W., Giegling, I., Mavrogiorgou, P., Pogarell, O., Mulert, C., Moller, H.J., Hegerl, U., Rujescu, D., Juckel, G., 2008. Association of functional polymorphisms in NOS1 and NOS3 with loudness dependence of auditory evoked potentials. Int J Neuropsychopharmacol 11, 477-483.

Kiss, J.P., Vizi, E.S., 2001. Nitric oxide: a novel link between synaptic and nonsynaptic transmission. Trends Neurosci. 24, 211-215.

Kopf, J., Schecklmann, M., Hahn, T., Dieler, A.C., Herrmann, M.J., Fallgatter, A.J., Reif, A., 2012. NOS1 ex1f-VNTR polymorphism affects prefrontal oxygenation during response inhibition tasks. Hum Brain Mapp 33, 2561-2571.

Kremeyer, B., Garcia, J., Kymalainen, H., Wratten, N., Restrepo, G., Palacio, C., Miranda, A.L., Lopez, C., Restrepo, M., Bedoya, G., Brzustowicz, L.M., Ospina-Duque, J., Arbelaez, M.P., Ruiz-Linares, A., 2009. Evidence for a role of the NOS1AP (CAPON) gene in schizophrenia and its clinical dimensions: an association study in a South American population isolate. Hum Hered 67, 163-173. 
Liou, Y.J., Hong, C.J., Liu, H.C., Liu, C.Y., Liu, T.Y., Chen, I.C., Tsai, S.J., 2002. No association between the neuronal nitric oxide synthase gene polymorphism and Alzheimer Disease. Am J Med Genet 114, 687-688.

Miranda, A., Garcia, J., Lopez, C., Gordon, D., Palacio, C., Restrepo, G., Ortiz, J., Montoya, G., Cardeno, C., Calle, J., Lopez, M., Campo, O., Bedoya, G., Ruiz-Linares, A., Ospina-Duque, J., 2006. Putative association of the carboxy-terminal PDZ ligand of neuronal nitric oxide synthase gene (CAPON) with schizophrenia in a Colombian population. Schizophr Res 82, 283-285.

Navarro-Lerida, I., Martinez Moreno, M., Roncal, F., Gavilanes, F., Albar, J.P., RodriguezCrespo, I., 2004. Proteomic identification of brain proteins that interact with dynein light chain LC8. Proteomics 4, 339-346.

Nicodemus, K.K., Law, A.J., Radulescu, E., Luna, A., Kolachana, B., Vakkalanka, R., Rujescu, D., Giegling, I., Straub, R.E., McGee, K., Gold, B., Dean, M., Muglia, P., Callicott, J.H., Tan, H.Y., Weinberger, D.R., 2010. Biological validation of increased schizophrenia risk with NRG1, ERBB4, and AKT1 epistasis via functional neuroimaging in healthy controls. Arch Gen Psychiatry 67, 991-1001.

Nicodemus, K.K., Marenco, S., Batten, A.J., Vakkalanka, R., Egan, M.F., Straub, R.E., Weinberger, D.R., 2008. Serious obstetric complications interact with hypoxiaregulated/vascular-expression genes to influence schizophrenia risk. Mol Psychiatry 13, 873877.

O'Donoghue, T., Morris, D.W., Fahey, C., Da Costa, A., Foxe, J.J., Hoerold, D., Tropea, D., Gill, M., Corvin, A., Donohoe, G., 2012. A NOS1 variant implicated in cognitive performance influences evoked neural responses during a high density EEG study of early visual perception. Hum Brain Mapp 33, 1202-1211.

O'Donovan, M.C., Craddock, N., Norton, N., Williams, H., Peirce, T., Moskvina, V., Nikolov, I., Hamshere, M., Carroll, L., Georgieva, L., Dwyer, S., Holmans, P., Marchini, J.L., Spencer, C.C., Howie, B., Leung, H.T., Hartmann, A.M., Moller, H.J., Morris, D.W., Shi, Y., Feng, G., Hoffmann, P., Propping, P., Vasilescu, C., Maier, W., Rietschel, M., Zammit, S., Schumacher, J., Quinn, E.M., Schulze, T.G., Williams, N.M., Giegling, I., Iwata, N., Ikeda, M., Darvasi, A., Shifman, S., He, L., Duan, J., Sanders, A.R., Levinson, D.F., Gejman, P.V., Cichon, S., Nothen, M.M., Gill, M., Corvin, A., Rujescu, D., Kirov, G., Owen, M.J., Buccola, N.G., Mowry, B.J., Freedman, R., Amin, F., Black, D.W., Silverman, J.M., Byerley, W.F., Cloninger, C.R., 2008. Identification of loci associated with schizophrenia by genome-wide association and followup. Nat Genet 40, 1053-1055.

Okumura, T., Okochi, T., Kishi, T., Ikeda, M., Kitajima, T., Yamanouchi, Y., Kinoshita, Y., Kawashima, K., Tsunoka, T., Ujike, H., Inada, T., Ozaki, N., Iwata, N., 2009. No association between polymorphisms of neuronal oxide synthase 1 gene (NOS1) and schizophrenia in a Japanese population. Neuromolecular Med 11, 123-127.

Palsson, E., Lowry, J., Klamer, D., 2010. Information processing deficits and nitric oxide signalling in the phencyclidine model of schizophrenia. Psychopharmacology (Berl) 212, 643651.

Puri, V., McQuillin, A., Choudhury, K., Datta, S., Pimm, J., Thirumalai, S., Krasucki, R., Lawrence, J., Quested, D., Bass, N., Moorey, H., Morgan, J., Punukollu, B., Kandasami, G., 
Curtis, D., Gurling, H., 2007. Fine mapping by genetic association implicates the chromosome 1q23.3 gene UHMK1, encoding a serine/threonine protein kinase, as a novel schizophrenia susceptibility gene. Biol Psychiatry 61, 873-879.

Puri, V., McQuillin, A., Thirumalai, S., Lawrence, J., Krasucki, R., Choudhury, K., Datta, S., Kerwin, S., Quested, D., Bass, N., Pimm, J., Lamb, G., Moorey, H., Kandasami, G., Badacsonyi, A., Kelly, K., Morgan, J., Punukollu, B., Nadeem, H., Curtis, D., Gurling, H.M., 2006. Failure to confirm allelic association between markers at the CAPON gene locus and schizophrenia in a British sample. Biol Psychiatry 59, 195-197.

Reif, A., Herterich, S., Strobel, A., Ehlis, A.C., Saur, D., Jacob, C.P., Wienker, T., Topner, T., Fritzen, S., Walter, U., Schmitt, A., Fallgatter, A.J., Lesch, K.P., 2006. A neuronal nitric oxide synthase (NOS-I) haplotype associated with schizophrenia modifies prefrontal cortex function. Mol Psychiatry, 286-300.

Reif, A., Kiive, E., Kurrikoff, T., Paaver, M., Herterich, S., Konstabel, K., Tulviste, T., Lesch, K.P., Harro, J., 2011. A functional NOS1 promoter polymorphism interacts with adverse environment on functional and dysfunctional impulsivity. Psychopharmacology (Berl).

Riley, B., Thiselton, D., Maher, B.S., Bigdeli, T., Wormley, B., McMichael, G.O., Fanous, A.H., Vladimirov, V., O'Neill, F.A., Walsh, D., Kendler, K.S., 2010. Replication of association between schizophrenia and ZNF804A in the Irish Case-Control Study of Schizophrenia sample. Mol Psychiatry 15, 29-37.

Rodriguez-Crespo, I., Yelamos, B., Roncal, F., Albar, J.P., Ortiz de Montellano, P.R., Gavilanes, F., 2001. Identification of novel cellular proteins that bind to the LC8 dynein light chain using a pepscan technique. FEBS Lett 503, 135-141.

Rose, E.J., Greene, C., Kelly, S., Morris, D.W., Robertson, I.H., Fahey, C., Jacobson, S., O'Doherty, J., Newell, F.N., McGrath, J., Bokde, A., Garavan, H., Frodl, T., Gill, M., Corvin, A.P., Donohoe, G., 2012. The NOS1 variant rs6490121 is associated with variation in prefrontal function and grey matter density in healthy individuals. Neuroimage 60, 614-622.

Saur, D., Vanderwinden, J.M., Seidler, B., Schmid, R.M., De Laet, M.H., Allescher, H.D., 2004. Single-nucleotide promoter polymorphism alters transcription of neuronal nitric oxide synthase exon 1c in infantile hypertrophic pyloric stenosis. Proc Natl Acad Sci U S A 101, 1662-1667.

Saviouk, V., Moreau, M.P., Tereshchenko, I.V., Brzustowicz, L.M., 2007. Association of synapsin 2 with schizophrenia in families of Northern European ancestry. Schizophr Res 96, 100-111.

Shinkai, T., Ohmori, O., Hori, H., Nakamura, J., 2002. Allelic association of the neuronal nitric oxide synthase (NOS1) gene with schizophrenia. Mol Psychiatry 7, 560-563.

Silberberg, G., Ben-Shachar, D., Navon, R., 2010. Genetic analysis of nitric oxide synthase 1 variants in schizophrenia and bipolar disorder. Am J Med Genet B Neuropsychiatr Genet 153B, 1318-1328.

Tang, W., Huang, K., Tang, R., Zhou, G., Fang, C., Zhang, J., Du, L., Feng, G., He, L., Shi, Y., 2008. Evidence for association between the 5 ' flank of the NOS1 gene and schizophrenia in the Chinese population. Int J Neuropsychopharmacol 11, 1063-1071. 
Wang, J., Ma, X.H., Xiang, B., Wu, J.Y., Wang, Y.C., Deng, W., Li, M.L., Wang, Q., He, Z.L., Li, T., 2012. [Association study of NOS1 gene polymorphisms and schizophrenia]. Zhonghua Yi Xue Yi Chuan Xue Za Zhi 29, 459-463.

Wratten, N.S., Memoli, H., Huang, Y., Dulencin, A.M., Matteson, P.G., Cornacchia, M.A., Azaro, M.A., Messenger, J., Hayter, J.E., Bassett, A.S., Buyske, S., Millonig, J.H., Vieland, V.J., Brzustowicz, L.M., 2009. Identification of a schizophrenia-associated functional noncoding variant in NOS1AP. Am J Psychiatry 166, 434-441.

Xu, B., Wratten, N., Charych, E.I., Buyske, S., Firestein, B.L., Brzustowicz, L.M., 2005. Increased expression in dorsolateral prefrontal cortex of CAPON in schizophrenia and bipolar disorder. PLoS Med 2, e263.

Zheng, Y., Li, H., Qin, W., Chen, W., Duan, Y., Xiao, Y., Li, C., Zhang, J., Li, X., Feng, G., He, L., 2005. Association of the carboxyl-terminal PDZ ligand of neuronal nitric oxide synthase gene with schizophrenia in the Chinese Han population. Biochem Biophys Res Commun 328, 809815.

Zoubovsky, S.P., Pogorelov, V.M., Taniguchi, Y., Kim, S.H., Yoon, P., Nwulia, E., Sawa, A., Pletnikov, M.V., Kamiya, A., 2011. Working memory deficits in neuronal nitric oxide synthase knockout mice: potential impairments in prefrontal cortex mediated cognitive function. Biochem Biophys Res Commun 408, 707-712. 


\section{Figures}

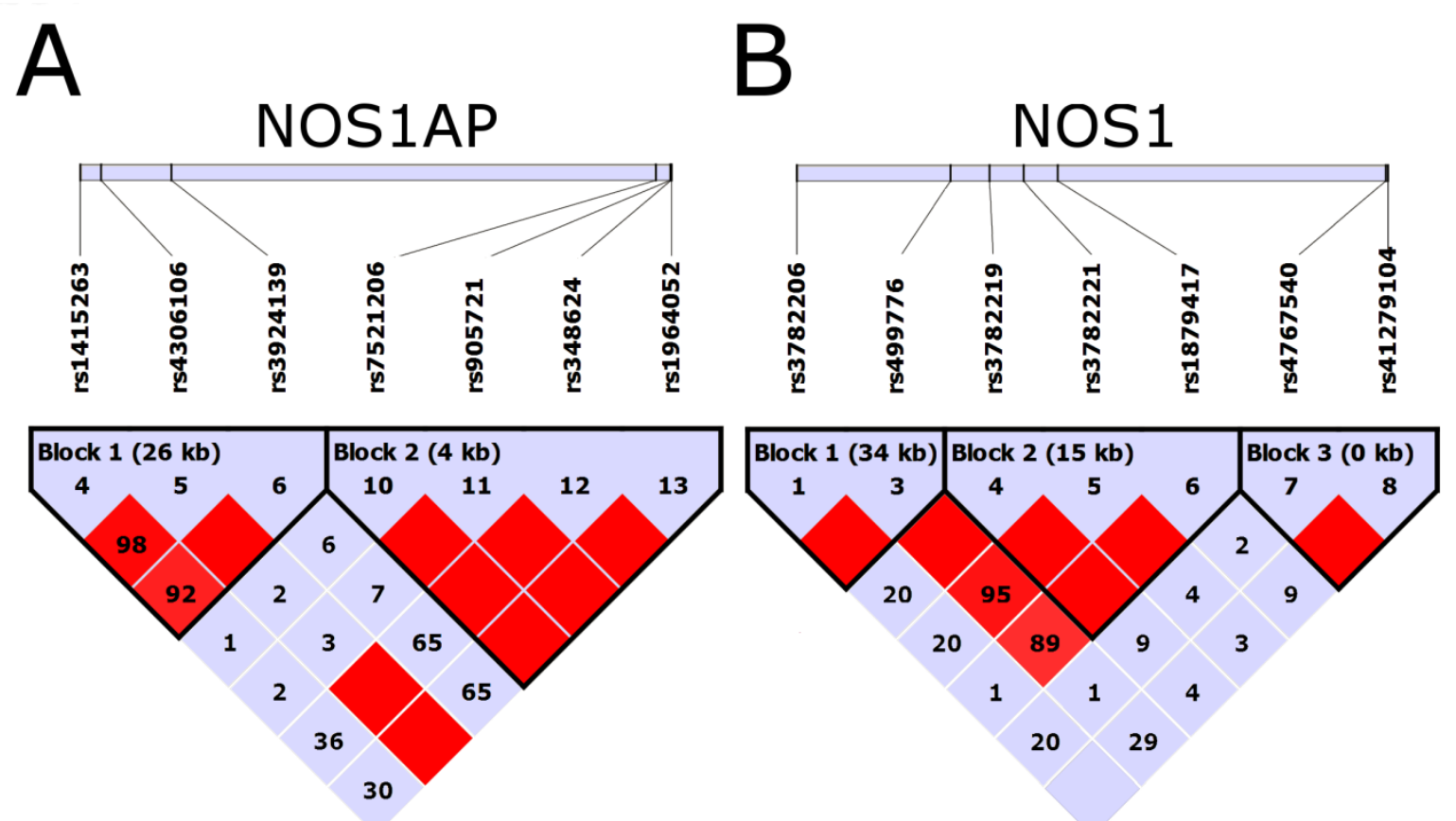

Figure 1: Linkage disequilibrium (LD) plots of $\operatorname{NOS1AP}(\mathbf{A})$ and NOS1 (B). LD is displayed as D' Haplotype blocks as defined by the solid spine method. 
A

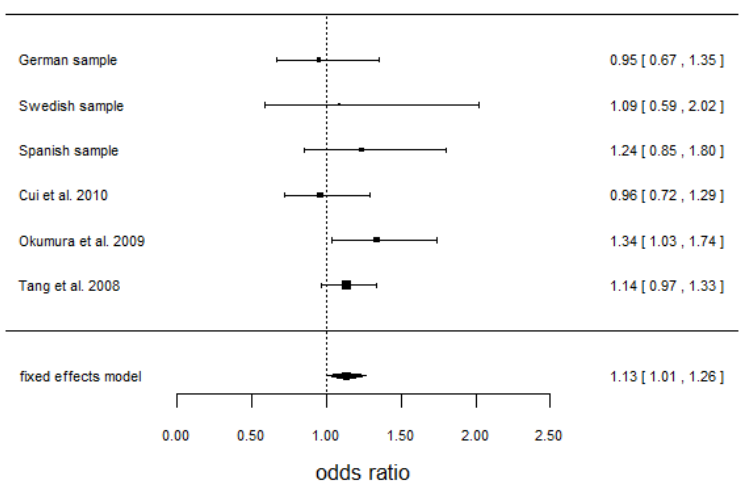

B

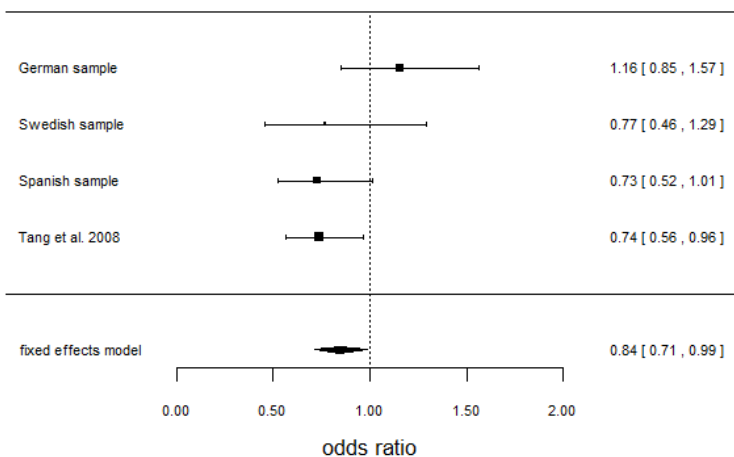

C

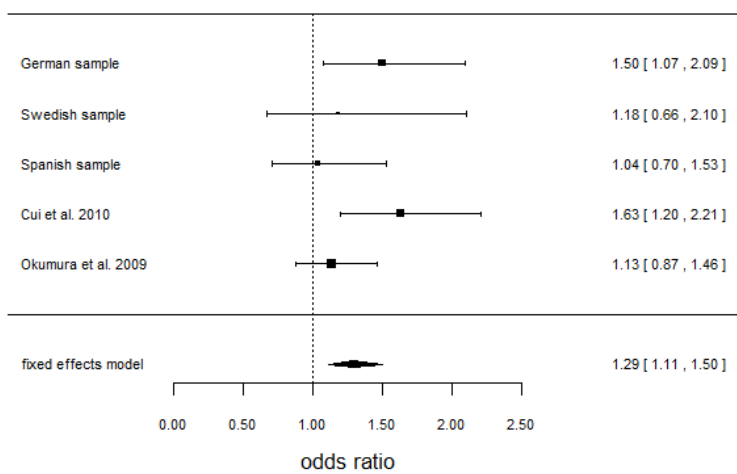

rs3782206 allelic model

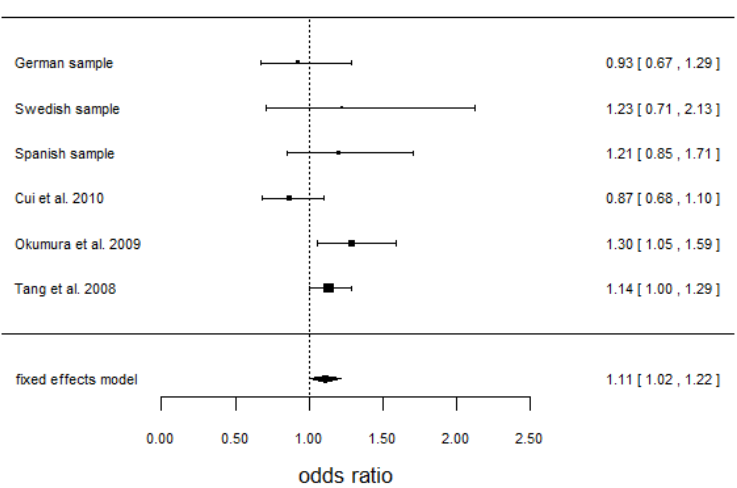

rs499776 allelic model

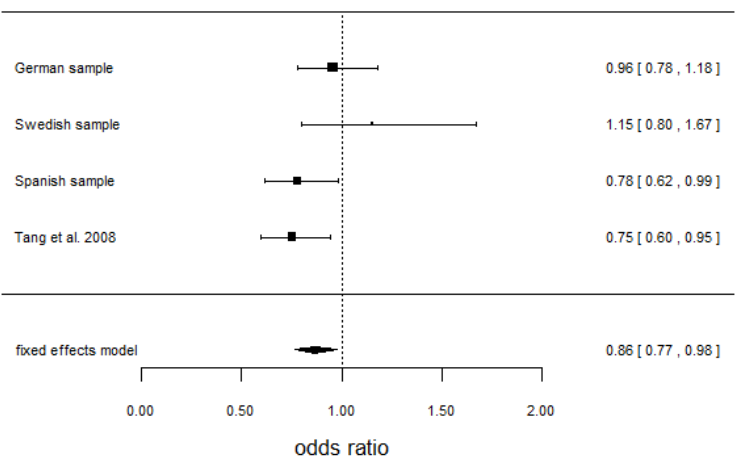

rs41279104 allelic model

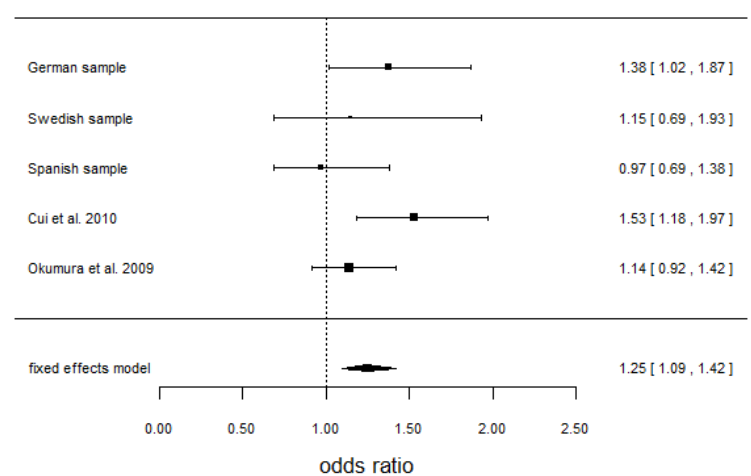

Figure 2: Forest plots of NOS1AP rs3782206 dominant and allelic model (A), NOS1 rs499776 dominant and allelic model (B) and NOS1 rs41279104 dominant and allelic model (C) 
Table 1: Association results for examined SNPs along with their chromosomal position, minor/major alleles, genotype and allele counts for cases and controls, the nominal p-value of Fisher's exact tests of a genotypic, allelic and dominant model and the respective Bonferroni-corrected p-values for the German, Swedish and Spanish samples. Bold indicates SNPs with at least one significant $p$-value $(p<0.05)$ in one or more of the three calculated models. Chromosomal positions were given according to the latest NCBI Genome assembly GRCh37.p5.

\begin{tabular}{|c|c|c|c|c|c|c|c|c|c|c|c|c|c|c|c|}
\hline \multirow[b]{3}{*}{ SNP } & \multirow{3}{*}{$\begin{array}{l}\text { Chromosomal } \\
\text { Position (bp) }\end{array}$} & \multirow{3}{*}{$\begin{array}{l}\text { Allele } \\
\text { (d/D) }\end{array}$} & \multirow[b]{3}{*}{ Association Model } & \multicolumn{4}{|c|}{ German sample } & \multicolumn{4}{|c|}{ Swedish sample } & \multicolumn{4}{|c|}{ Spanish sample } \\
\hline & & & & \multicolumn{2}{|c|}{ Number of Genotypes } & \multirow{2}{*}{$\begin{array}{l}\text { Nominal } \\
\text { P-value }\end{array}$} & \multirow{2}{*}{$\begin{array}{l}\text { Bonferroni } \\
\text { P-value }\end{array}$} & \multicolumn{2}{|c|}{ Number of Genotypes } & \multirow{2}{*}{$\begin{array}{l}\text { Nominal } \\
\text { P-value }\end{array}$} & \multirow{2}{*}{$\begin{array}{l}\text { Bonferroni } \\
\text { P-value }\end{array}$} & \multicolumn{2}{|c|}{ Number of Genotypes } & \multirow{2}{*}{$\begin{array}{l}\text { Nominal } \\
\text { P-value }\end{array}$} & \multirow{2}{*}{$\begin{array}{l}\text { Bonferroni } \\
\text { P-value }\end{array}$} \\
\hline & & & & $\begin{array}{l}\text { Controls } \\
(n=720)\end{array}$ & $\begin{array}{c}\text { Cases } \\
(n=270)\end{array}$ & & & $\begin{array}{c}\text { Controls } \\
(n=168)\end{array}$ & $\begin{array}{l}\text { Cases } \\
(n=101)\end{array}$ & & & $\begin{array}{c}\text { Controls } \\
(n=360)\end{array}$ & $\begin{array}{c}\text { Cases } \\
(n=270)\end{array}$ & & \\
\hline \multicolumn{16}{|c|}{ NOS1AP (Capon); Chromosome 1: } \\
\hline \multirow[t]{3}{*}{ rs1572495 } & 162099301 & $\mathrm{~T} / \mathrm{C}$ & Genotypic n(dd/dD/DD) & $7 / 108 / 587$ & $3 / 39 / 213$ & 0,936 & 1 & $1 / 22 / 140$ & $0 / 11 / 89$ & 0,735 & 1 & $2 / 56 / 284$ & $4 / 41 / 223$ & 0,552 & 1 \\
\hline & & & Allelic $n(d / D)$ & $122 / 1282$ & $45 / 465$ & 0,927 & 1 & $24 / 302$ & $11 / 189$ & 0,474 & 1 & $60 / 624$ & $49 / 487$ & 0,840 & 1 \\
\hline & & & Dominant $n(d d+d D / D D)$ & $115 / 587$ & $42 / 213$ & 1,000 & 1 & $23 / 140$ & $11 / 89$ & 0,571 & 1 & $58 / 284$ & $45 / 223$ & 1,000 & 1 \\
\hline \multirow[t]{3}{*}{ rs1538018 } & 162130481 & C/G & Genotypic n(dd/dD/DD) & -- & -- & -- & -- & $8 / 57 / 90$ & $8 / 35 / 54$ & 0,620 & 1 & -- & -- & -- & -- \\
\hline & & & Allelic $n(d / D)$ & -- & -- & -- & -- & $73 / 237$ & $51 / 143$ & 0,524 & 1 & -- & -- & -- & -- \\
\hline & & & Dominant $n(d d+d D / D D)$ & -- & -- & -- & -- & $65 / 90$ & $43 / 54$ & 0,794 & 1 & -- & -- & -- & -- \\
\hline \multirow[t]{3}{*}{ rs945713 } & 162135670 & $C / T$ & Genotypic $n(d d / d D / D D)$ & $102 / 339 / 257$ & $57 / 130 / 73$ & 0,006 & 0,167 & $36 / 71 / 49$ & $12 / 48 / 37$ & 0,101 & 1 & $63 / 162 / 118$ & $49 / 139 / 79$ & 0,413 & 1 \\
\hline & & & Allelic $n(d / D)$ & $543 / 853$ & $244 / 276$ & 0,002 & 0,048 & $143 / 169$ & $72 / 122$ & 0,064 & 1 & $288 / 398$ & $237 / 297$ & 0,415 & 1 \\
\hline & & & Dominant $n(d d+d D / D D)$ & $441 / 257$ & $187 / 73$ & 0,012 & 0,326 & $107 / 49$ & $60 / 37$ & 0,278 & 1 & $225 / 118$ & $188 / 79$ & 0,222 & 1 \\
\hline \multirow[t]{2}{*}{ rs1415263 } & 162166043 & $T / C$ & Genotypic $n(d d / d D / D D)$ & $107 / 333 / 262$ & $43 / 134 / 78$ & 0,155 & 1 & $38 / 79 / 44$ & $10 / 51 / 38$ & 0,012 & 0,353 & $71 / 162 / 108$ & $50 / 138 / 77$ & 0,532 & 1 \\
\hline & & & Allelic $n(d / D)$ & $547 / 857$ & $220 / 290$ & 0,102 & 1 & $155 / 167$ & $71 / 127$ & 0,006 & 0,191 & $304 / 378$ & $238 / 292$ & 0,954 & 1 \\
\hline \multirow[t]{3}{*}{ rs 4306106} & 162171994 & $A / G$ & Genotypic n(dd/dD/DD) & $36 / 217 / 442$ & $14 / 93 / 151$ & 0,337 & 1 & $16 / 64 / 75$ & $3 / 35 / 59$ & 0,042 & 1 & $29 / 139 / 175$ & $16 / 118 / 132$ & 0,419 & 1 \\
\hline & & & Allelic $n(d / D)$ & $289 / 1101$ & $121 / 395$ & 0,210 & 1 & $96 / 214$ & $41 / 153$ & 0,018 & 0,536 & $197 / 489$ & $150 / 382$ & 0,848 & 1 \\
\hline & & & Dominant $n(d d+d D / D D)$ & $253 / 442$ & $107 / 151$ & 0,154 & 1 & $80 / 75$ & $38 / 59$ & 0,069 & 1 & $168 / 175$ & $134 / 132$ & 0,744 & 1 \\
\hline \multirow[t]{3}{*}{ rs3924139 } & 162192112 & $\mathrm{G} / \mathrm{A}$ & Genotypic $n(d d / d D / D D)$ & $84 / 325 / 288$ & $40 / 122 / 97$ & 0,303 & 1 & $33 / 79 / 45$ & $7 / 49 / 41$ & 0,004 & 0,128 & $65 / 154 / 126$ & $41 / 139 / 87$ & 0,179 & 1 \\
\hline & & & Allelic $n(d / D)$ & 493/901 & $202 / 316$ & 0,149 & 1 & $145 / 169$ & $63 / 131$ & 0,003 & 0,087 & $284 / 406$ & $221 / 313$ & 0,953 & 1 \\
\hline & & & Dominant $n(d d+d D / D D)$ & $409 / 288$ & $162 / 97$ & 0,299 & 1 & $112 / 45$ & $56 / 41$ & 0,029 & 0,884 & $219 / 126$ & $180 / 87$ & 0,347 & 1 \\
\hline \multirow[t]{3}{*}{ rs1508263 } & 162279509 & A/G & Genotypic $n(d d / d D / D D)$ & 139/358/199 & $46 / 119 / 80$ & 0,490 & 1 & $34 / 68 / 51$ & $25 / 49 / 21$ & 0,166 & 1 & $69 / 176 / 97$ & $30 / 142 / 94$ & 0,007 & 0,187 \\
\hline & & & Allelic $n(d / D)$ & $636 / 756$ & $211 / 279$ & 0,317 & 1 & $136 / 170$ & $99 / 91$ & 0,116 & 1 & $314 / 370$ & $202 / 330$ & 0,006 & 0,155 \\
\hline & & & Dominant $n(d d+d D / D D)$ & $497 / 199$ & $165 / 80$ & 0,255 & 1 & $102 / 51$ & $74 / 21$ & 0,063 & 1 & $245 / 97$ & $172 / 94$ & 0,078 & 1 \\
\hline \multirow[t]{3}{*}{ rs3751284 } & 162313735 & A/G & Genotypic $n(d d / d D / D D)$ & $90 / 307 / 298$ & $29 / 116 / 110$ & 0,825 & 1 & $30 / 65 / 67$ & $8 / 54 / 38$ & 0,022 & 0,653 & $32 / 168 / 136$ & $33 / 111 / 123$ & 0,104 & 1 \\
\hline & & & Allelic $n(d / D)$ & $487 / 903$ & $174 / 336$ & 0,744 & 1 & $125 / 199$ & $70 / 130$ & 0,457 & 1 & $232 / 440$ & $177 / 357$ & 0,625 & 1 \\
\hline & & & Dominant $n(d d+d D / D D)$ & $397 / 298$ & $145 / 110$ & 0,941 & 1 & $95 / 67$ & $62 / 38$ & 0,606 & 1 & $200 / 136$ & $144 / 123$ & 0,185 & 1 \\
\hline
\end{tabular}




\begin{tabular}{|c|c|c|c|c|c|c|c|c|c|c|c|c|c|c|c|}
\hline \multirow[t]{3}{*}{ rs7521206 } & 162330927 & $\mathrm{G} / \mathrm{C}$ & Genotypic n(dd/dD/DD) & $91 / 323 / 288$ & $35 / 113 / 107$ & 0,888 & 1 & $20 / 85 / 59$ & $13 / 53 / 34$ & 0,935 & 1 & $47 / 172 / 123$ & $34 / 128 / 106$ & 0,659 & 1 \\
\hline & & & Allelic $n(d / D)$ & $505 / 899$ & $183 / 327$ & 1,000 & 1 & $125 / 203$ & $79 / 121$ & 0,783 & 1 & $266 / 418$ & $196 / 340$ & 0,440 & 1 \\
\hline & & & Dominant n(dd+dD/DD) & $414 / 288$ & $148 / 107$ & 0,824 & 1 & $105 / 59$ & $66 / 34$ & 0,791 & 1 & $219 / 123$ & $162 / 106$ & 0,400 & 1 \\
\hline \multirow[t]{3}{*}{ rs905721 } & 162335052 & $T / C$ & Genotypic n(dd/dD/DD) & $94 / 322 / 282$ & $38 / 116 / 104$ & 0,868 & 1 & $18 / 80 / 59$ & $13 / 51 / 33$ & 0,811 & 1 & $49 / 171 / 122$ & $33 / 130 / 105$ & 0,605 & 1 \\
\hline & & & Allelic $n(d / D)$ & $510 / 886$ & $192 / 324$ & 0,790 & 1 & $116 / 198$ & $77 / 117$ & 0,573 & 1 & $269 / 415$ & $196 / 340$ & 0,342 & 1 \\
\hline & & & Dominant $n(d d+d D / D D)$ & $416 / 282$ & $154 / 104$ & 1,000 & 1 & $98 / 59$ & $64 / 33$ & 0,593 & 1 & $220 / 122$ & $163 / 105$ & 0,399 & 1 \\
\hline \multirow[t]{2}{*}{ rs348624 } & 162335256 & $T / C$ & Genotypic n(dd/dD/DD) & $10 / 141 / 537$ & $3 / 51 / 194$ & 1,000 & 1 & $2 / 23 / 135$ & $1 / 19 / 76$ & 0,584 & 1 & -- & - & -- & - \\
\hline & & & Allelic n(d/D) & $161 / 1215$ & $57 / 439$ & 0,935 & 1 & $27 / 293$ & $21 / 171$ & 0,352 & 1 & -- & -- & -- & -- \\
\hline \multirow[t]{3}{*}{ rs1964052 } & 162335424 & $T / C$ & Genotypic n(dd/dD/DD) & $10 / 145 / 545$ & $3 / 55 / 195$ & 0,948 & 1 & $2 / 25 / 136$ & $1 / 19 / 79$ & 0,777 & 1 & $2 / 70 / 268$ & $5 / 53 / 203$ & 0,394 & 1 \\
\hline & & & Allelic $n(d / D)$ & $165 / 1235$ & $61 / 445$ & 0,873 & 1 & $29 / 297$ & $21 / 177$ & 0,542 & 1 & $74 / 606$ & $63 / 459$ & 0,523 & 1 \\
\hline & & & Dominant $n(d d+d D / D D)$ & $155 / 545$ & $58 / 195$ & 0,792 & 1 & $27 / 136$ & $20 / 79$ & 0,508 & 1 & $72 / 268$ & $58 / 203$ & 0,765 & 1 \\
\hline \multicolumn{16}{|c|}{ sYN2; Chromosome 3: } \\
\hline \multirow[t]{3}{*}{ rs598747 } & 12112010 & $\mathrm{C} / \mathrm{T}$ & Genotypic n(dd/dD/DD) & $9 / 152 / 537$ & $6 / 57 / 190$ & 0,439 & 1 & $4 / 51 / 106$ & $3 / 28 / 69$ & 0,761 & 1 & -- & -- & -- & -- \\
\hline & & & Allelic $n(d / D)$ & $170 / 1226$ & $69 / 437$ & 0,390 & 1 & $59 / 263$ & $34 / 166$ & 0,726 & 1 & -- & - & -- & -- \\
\hline & & & Dominant $\mathrm{n}(\mathrm{dd}+\mathrm{dD} / \mathrm{DD})$ & $161 / 537$ & $63 / 190$ & 0,546 & 1 & $55 / 106$ & $31 / 69$ & 0,685 & 1 & -- & - & -- & - \\
\hline \multirow[t]{2}{*}{ rs598704 } & 12112053 & $\mathrm{C} / \mathrm{T}$ & Genotypic n(dd/dD/DD) & $40 / 254 / 403$ & $16 / 101 / 129$ & 0,329 & 1 & $17 / 67 / 73$ & $5 / 42 / 50$ & 0,291 & 1 & 21/139/185 & 17/108/142 & 1,000 & 1 \\
\hline & & & Dominant $\mathrm{n}(\mathrm{dd}+\mathrm{dD} / \mathrm{DD})$ & $294 / 403$ & $117 / 129$ & 0,156 & 1 & $84 / 73$ & $47 / 50$ & 0,442 & 1 & $160 / 185$ & $125 / 142$ & 0,935 & 1 \\
\hline \multirow[t]{3}{*}{ rs308969 } & 12177083 & $\mathrm{C} / \mathrm{T}$ & Genotypic n(dd/dD/DD) & $10 / 107 / 584$ & 0/47/208 & 0,080 & 1 & $2 / 34 / 128$ & $2 / 19 / 78$ & 0,824 & 1 & $3 / 70 / 269$ & $0 / 40 / 228$ & 0,049 & 1 \\
\hline & & & Allelic n(d/D) & $127 / 1275$ & $47 / 463$ & 0,928 & 1 & $38 / 290$ & $23 / 175$ & 1,000 & 1 & $76 / 608$ & $40 / 496$ & 0,039 & 1 \\
\hline & & & Dominant $n(d d+d D / D D)$ & $117 / 584$ & $47 / 208$ & 0,561 & 1 & $36 / 128$ & $21 / 78$ & 1,000 & 1 & $73 / 269$ & $40 / 228$ & 0,046 & 1 \\
\hline \multirow[t]{3}{*}{ rs3817004 } & 12195674 & G/A & Genotypic n(dd/dD/DD) & 0/42/656 & 2/17/236 & 0,098 & 1 & 0/16/148 & 0/8/92 & 0,826 & 1 & $1 / 23 / 316$ & $1 / 22 / 245$ & 0,770 & 1 \\
\hline & & & Allelic $n(d / D)$ & $42 / 1354$ & $21 / 489$ & 0,247 & 1 & $16 / 312$ & $8 / 192$ & 0,830 & 1 & $25 / 655$ & $24 / 512$ & 0,557 & 1 \\
\hline & & & Dominant $\mathrm{n}(\mathrm{dd}+\mathrm{dD} / \mathrm{DD})$ & $42 / 656$ & $19 / 236$ & 0,455 & 1 & $16 / 148$ & $8 / 92$ & 0,826 & 1 & $24 / 316$ & $23 / 245$ & 0,542 & 1 \\
\hline \multirow[t]{3}{*}{ ss35528972 } & 12197255 & $T / A$ & Genotypic n(dd/dD/DD) & $3 / 73 / 618$ & 0/30/227 & 0,636 & 1 & $1 / 21 / 135$ & $0 / 9 / 88$ & 0,644 & 1 & $2 / 48 / 294$ & 0/30/237 & 0,364 & 1 \\
\hline & & & Allelic $n(d / D)$ & $79 / 1309$ & $30 / 484$ & 0,912 & 1 & $23 / 291$ & $9 / 185$ & 0,263 & 1 & $52 / 636$ & $30 / 504$ & 0,205 & 1 \\
\hline & & & Dominant $\mathrm{n}(\mathrm{dd}+\mathrm{dD} / \mathrm{DD})$ & $76 / 618$ & $30 / 227$ & 0,729 & 1 & $22 / 135$ & $9 / 88$ & 0,326 & 1 & $50 / 294$ & $30 / 237$ & 0,277 & 1 \\
\hline \multirow[t]{3}{*}{ rs3755724 } & 12200906 & $T / C$ & Genotypic n(dd/dD/DD) & $71 / 294 / 327$ & $26 / 103 / 120$ & 0,959 & 1 & $19 / 84 / 54$ & $11 / 51 / 36$ & 0,932 & 1 & 29/149/149 & $33 / 102 / 127$ & 0,158 & 1 \\
\hline & & & Allelic $n(d / D)$ & $436 / 948$ & $155 / 343$ & 0,910 & 1 & 122/192 & $73 / 123$ & 0,779 & 1 & $207 / 447$ & $168 / 356$ & 0,900 & 1 \\
\hline & & & Dominant $n(d d+d D / D D)$ & $365 / 327$ & $129 / 120$ & 0,825 & 1 & $103 / 54$ & $62 / 36$ & 0,788 & 1 & $178 / 149$ & $135 / 127$ & 0,507 & 1 \\
\hline \multicolumn{16}{|c|}{ NOS1; Chromosome 12: } \\
\hline \multirow[t]{2}{*}{ rs3782206 } & 117745089 & $T / C$ & Genotypic n(dd/dD/DD) & $7 / 141 / 548$ & 1/52/206 & 0,835 & 1 & $2 / 30 / 126$ & $4 / 17 / 76$ & 0,347 & 1 & 2/72/268 & 2/66/199 & 0,530 & 1 \\
\hline & & & Allelic $n(d / D)$ & $155 / 1237$ & $54 / 464$ & 0,681 & 1 & $34 / 282$ & $25 / 169$ & 0,478 & 1 & $76 / 608$ & $70 / 464$ & 0,288 & 1 \\
\hline
\end{tabular}




\begin{tabular}{|c|c|c|c|c|c|c|c|c|c|c|c|c|c|c|c|}
\hline \multirow[t]{3}{*}{ rs499776 } & 117779499 & $A / G$ & Genotypic n(dd/dD/DD) & $123 / 331 / 243$ & $32 / 145 / 82$ & 0,038 & 1 & $12 / 90 / 55$ & $20 / 37 / 40$ & 0,002 & 0,046 & $58 / 166 / 119$ & $34 / 121 / 113$ & 0,117 & 1 \\
\hline & & & Allelic n(d/D) & $577 / 817$ & $209 / 309$ & 0,714 & 1 & $114 / 200$ & $77 / 117$ & 0,452 & 1 & $282 / 404$ & $189 / 347$ & 0,038 & 0,997 \\
\hline & & & Dominant $n(d d+d D / D D)$ & $454 / 243$ & $177 / 82$ & 0,398 & 1 & $102 / 55$ & $57 / 40$ & 0,351 & 1 & $224 / 119$ & $155 / 113$ & 0,065 & 1 \\
\hline \multirow[t]{3}{*}{ rs3782219 } & 117788240 & $T / C$ & -- & -- & -- & -- & -- & $4 / 55 / 100$ & $6 / 23 / 68$ & 0,080 & 1 & -- & -- & -- & -- \\
\hline & & & - & - & - & -- & -- & $63 / 255$ & $35 / 159$ & 0,645 & 1 & -- & - & -- & -- \\
\hline & & & -- & -- & - & -- & -- & $59 / 100$ & $29 / 68$ & 0,278 & 1 & -- & - & -- & -- \\
\hline \multirow[t]{3}{*}{ rs3782221 } & 117795881 & $A / G$ & Genotypic n(dd/dD/DD) & $31 / 244 / 420$ & $13 / 93 / 146$ & 0,740 & 1 & $5 / 62 / 92$ & $7 / 26 / 67$ & 0,052 & 1 & $17 / 127 / 196$ & 23/95/144 & 0,184 & 1 \\
\hline & & & Allelic $n(d / D)$ & $306 / 1084$ & $119 / 385$ & 0,455 & 1 & $72 / 246$ & $40 / 160$ & 0,512 & 1 & $161 / 519$ & $141 / 383$ & 0,203 & 1 \\
\hline & & & Dominant $\mathrm{n}(\mathrm{dd}+\mathrm{dD} / \mathrm{DD})$ & $275 / 420$ & $106 / 146$ & 0,500 & 1 & $67 / 92$ & $33 / 67$ & 0,151 & 1 & $144 / 196$ & $118 / 144$ & 0,562 & 1 \\
\hline \multirow[t]{3}{*}{ rs1879417 } & 117803515 & $\mathrm{~T} / \mathrm{C}$ & Genotypic n(dd/dD/DD) & $163 / 349 / 178$ & $65 / 130 / 57$ & 0,561 & 1 & 26/91/45 & $28 / 43 / 28$ & 0,044 & 1 & $72 / 169 / 97$ & $51 / 132 / 84$ & 0,702 & 1 \\
\hline & & & Allelic $n(d / D)$ & $675 / 705$ & $260 / 244$ & 0,323 & 1 & $143 / 181$ & 99/99 & 0,206 & 1 & $313 / 363$ & $234 / 300$ & 0,416 & 1 \\
\hline & & & Dominant n(dd+dD/DD) & $512 / 178$ & $195 / 57$ & 0,350 & 1 & $117 / 45$ & $71 / 28$ & 1,000 & 1 & $241 / 97$ & $183 / 84$ & 0,475 & 1 \\
\hline \multirow[t]{3}{*}{ rs4767540 } & 117877007 & $\mathrm{G} / \mathrm{A}$ & Genotypic n(dd/dD/DD) & $160 / 324 / 213$ & $64 / 122 / 71$ & 0,638 & 1 & $28 / 76 / 51$ & $17 / 42 / 36$ & 0,688 & 1 & 67/160/118 & $47 / 129 / 89$ & 0,817 & 1 \\
\hline & & & Allelic $n(d / D)$ & $644 / 750$ & $250 / 264$ & 0,352 & 1 & $132 / 178$ & $76 / 114$ & 0,577 & 1 & $294 / 396$ & $223 / 307$ & 0,861 & 1 \\
\hline & & & Dominant $n(d d+d D / D D)$ & $484 / 213$ & $186 / 71$ & 0,425 & 1 & $104 / 51$ & $59 / 36$ & 0,494 & 1 & $227 / 118$ & $176 / 89$ & 0,931 & 1 \\
\hline \multirow[t]{3}{*}{ rs41279104 } & 117877485 & $\mathrm{~T} / \mathrm{C}$ & Genotypic n(dd/dD/DD) & $8 / 130 / 559$ & $2 / 66 / 184$ & 0,035 & 0,979 & $3 / 35 / 124$ & $2 / 24 / 72$ & 0,877 & 1 & $9 / 64 / 268$ & $4 / 55 / 209$ & 0,567 & 1 \\
\hline & & & Allelic n(d/D) & $146 / 1248$ & $70 / 434$ & 0,041 & 1 & $41 / 283$ & $28 / 168$ & 0,596 & 1 & $82 / 600$ & $63 / 473$ & 0,929 & 1 \\
\hline & & & Dominant $n(d d+d D / D D)$ & $138 / 559$ & $68 / 184$ & 0,020 & 0,571 & $38 / 124$ & $26 / 72$ & 0,656 & 1 & $73 / 268$ & $59 / 209$ & 0,921 & 1 \\
\hline \multicolumn{16}{|c|}{ DYNLL1 (PIN); Chromosome 12: } \\
\hline \multirow[t]{3}{*}{ rs12857 } & 120933946 & $T / G$ & Genotypic n(dd/dD/DD) & 21/202/471 & $11 / 64 / 174$ & 0,374 & 1 & $7 / 47 / 103$ & $4 / 34 / 59$ & 0,679 & 1 & 17/101/186 & $11 / 76 / 170$ & 0,452 & 1 \\
\hline & & & Allelic $n(d / D)$ & $244 / 1144$ & $86 / 412$ & 0,945 & 1 & $61 / 253$ & $42 / 152$ & 0,571 & 1 & $135 / 473$ & $98 / 416$ & 0,210 & 1 \\
\hline & & & Dominant $n(d d+d D / D D)$ & $223 / 471$ & $75 / 174$ & 0,579 & 1 & $54 / 103$ & $38 / 59$ & 0,502 & 1 & $118 / 186$ & $87 / 170$ & 0,253 & 1 \\
\hline \multirow[t]{3}{*}{ rs787828 } & 120937086 & $\mathrm{~T} / \mathrm{A}$ & Genotypic n(dd/dD/DD) & $86 / 296 / 320$ & $27 / 128 / 99$ & 0,081 & 1 & 20/70/70 & $10 / 41 / 48$ & 0,722 & 1 & $51 / 155 / 136$ & $47 / 121 / 100$ & 0,644 & 1 \\
\hline & & & Allelic n(d/D) & $468 / 936$ & $182 / 326$ & 0,325 & 1 & $110 / 210$ & $61 / 137$ & 0,442 & 1 & $257 / 427$ & $215 / 321$ & 0,375 & 1 \\
\hline & & & Dominant $n(d d+d D / D D)$ & $382 / 320$ & $155 / 99$ & 0,077 & 1 & $90 / 70$ & $51 / 48$ & 0,521 & 1 & $206 / 136$ & $168 / 100$ & 0,558 & 1 \\
\hline \multirow[t]{3}{*}{ rs9788155 } & 120938408 & $A / G$ & Genotypic n(dd/dD/DD) & $68 / 292 / 338$ & $23 / 105 / 131$ & 0,845 & 1 & $16 / 65 / 76$ & $12 / 38 / 46$ & 0,867 & 1 & 22/123/197 & $26 / 101 / 141$ & 0,242 & 1 \\
\hline & & & Allelic $n(d / D)$ & $428 / 968$ & $151 / 367$ & 0,538 & 1 & $97 / 217$ & $62 / 130$ & 0,768 & 1 & $167 / 517$ & $153 / 383$ & 0,116 & 1 \\
\hline & & & Dominant $\mathrm{n}(\mathrm{dd}+\mathrm{dD} / \mathrm{DD})$ & $360 / 338$ & $128 / 131$ & 0,561 & 1 & $81 / 76$ & $50 / 46$ & 1,000 & 1 & 145/197 & $127 / 141$ & 0,220 & 1 \\
\hline \multicolumn{16}{|c|}{ RASD1 (DEXRAS1); Chromosome 17: } \\
\hline \multirow[t]{3}{*}{ rs4924755 } & 17397131 & $\mathrm{G} / \mathrm{C}$ & Genotypic n(dd/dD/DD) & $60 / 280 / 363$ & 16/100/137 & 0,515 & 1 & 7/48/108 & $1 / 33 / 65$ & 0,340 & 1 & $33 / 133 / 175$ & $31 / 110 / 127$ & 0,561 & 1 \\
\hline & & & Allelic $n(d / D)$ & $400 / 1006$ & $132 / 374$ & 0,326 & 1 & $62 / 264$ & $35 / 163$ & 0,729 & 1 & $199 / 483$ & $172 / 364$ & 0,287 & 1 \\
\hline & & & Dominant $n(d d+d D / D D)$ & $340 / 363$ & $116 / 137$ & 0,510 & 1 & $55 / 108$ & $34 / 65$ & 1,000 & 1 & $166 / 175$ & $141 / 127$ & 0,369 & 1 \\
\hline \multirow[t]{3}{*}{ rs711352 } & 17397818 & $\mathrm{C} / \mathrm{G}$ & Genotypic n(dd/dD/DD) & $56 / 261 / 378$ & $13 / 92 / 144$ & 0,300 & 1 & 7/43/108 & $1 / 30 / 67$ & 0,319 & 1 & 24/124/189 & $25 / 107 / 136$ & 0,351 & 1 \\
\hline & & & Allelic n(d/D) & $373 / 1017$ & $118 / 380$ & 0,190 & 1 & $57 / 259$ & $32 / 164$ & 0,719 & 1 & $172 / 502$ & $157 / 379$ & 0,153 & 1 \\
\hline & & & Dominant $n(d d+d D / D D)$ & $317 / 378$ & 105/144 & 0,373 & 1 & $50 / 108$ & $31 / 67$ & 1,000 & 1 & $148 / 189$ & $132 / 136$ & 0,218 & 1 \\
\hline
\end{tabular}


Table 2: Association results for haplotypes examined in the German, Swedish and Spanish samples along with frequencies in cases and controls, nominal Pvalues of $x 2-T e s t s$ in one degree of freedom and the Bonferroni-corrected $p$-values, corrected over all haplotypes. Bold indicates significant haplotypes $p<0.05$ in at least one sample.

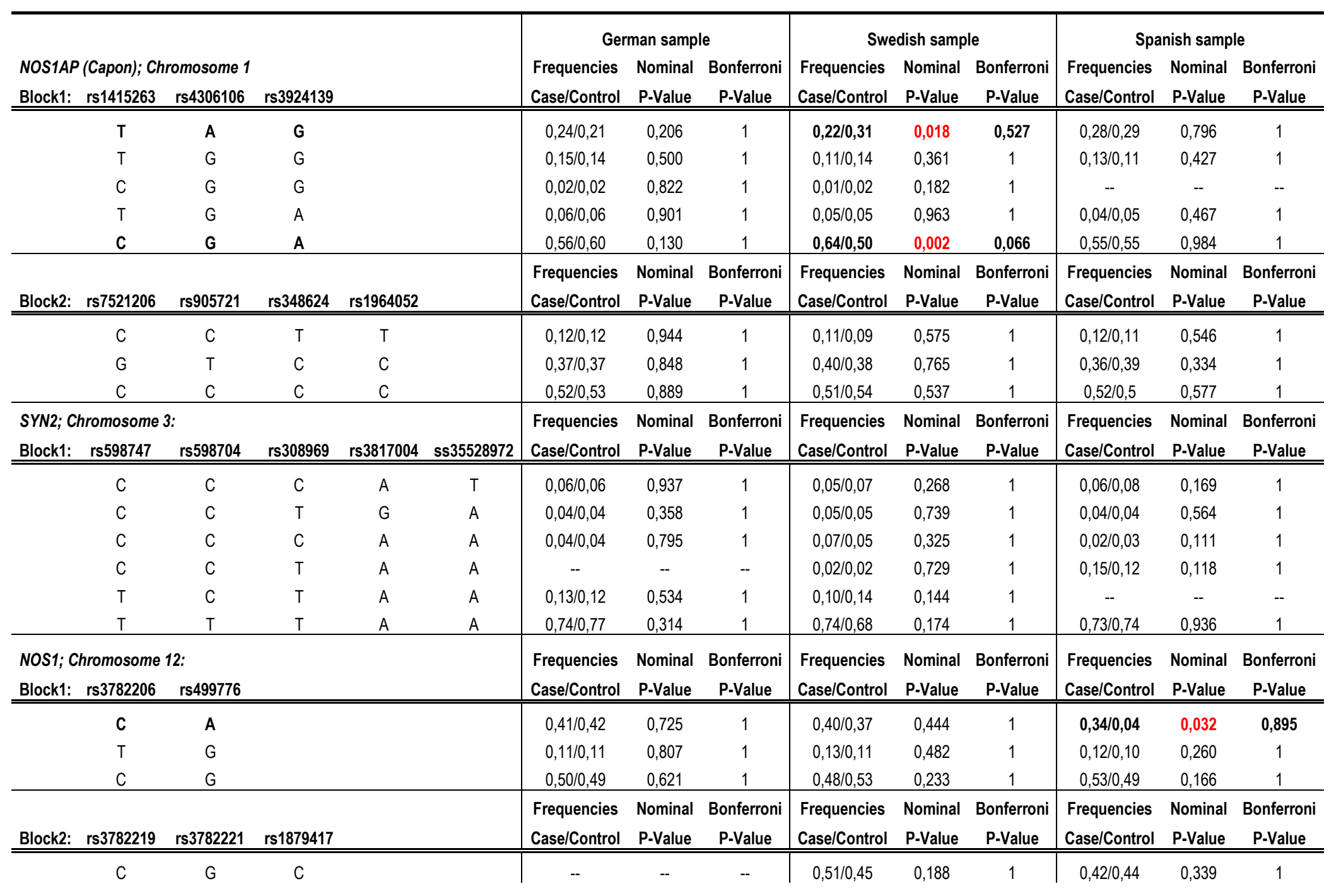




\begin{tabular}{|c|c|c|c|c|c|c|c|c|c|c|c|c|}
\hline \multirow{2}{*}{\multicolumn{2}{|c|}{$\begin{array}{r}\mathrm{T} \\
\mathrm{C} \\
\end{array}$}} & $A$ & $\mathrm{~T}$ & -- & -- & -- & $0,20 / 0,22$ & 0,507 & 1 & $0,24 / 0,22$ & 0,284 & 1 \\
\hline & & G & $T$ & -- & -- & -- & $0,31 / 0,34$ & 0,409 & 1 & $0,32 / 0,32$ & 0,954 & 1 \\
\hline \multirow[t]{4}{*}{ Block3: } & rs4767540 & rs41279104 & & $\begin{array}{l}\text { Frequencies } \\
\text { Case/Control }\end{array}$ & $\begin{array}{l}\text { Nominal } \\
\text { P-Value }\end{array}$ & $\begin{array}{c}\text { Bonferroni } \\
\text { P-Value }\end{array}$ & $\begin{array}{l}\text { Frequencies } \\
\text { Case/Control }\end{array}$ & $\begin{array}{l}\text { Nominal } \\
\text { P-Value }\end{array}$ & $\begin{array}{c}\text { Bonferroni } \\
\text { P-Value } \\
\end{array}$ & $\begin{array}{l}\text { Frequencies } \\
\text { Case/Control }\end{array}$ & $\begin{array}{l}\text { Nominal } \\
\text { P-Value } \\
\end{array}$ & $\begin{array}{c}\text { Bonferron } \\
\text { P-Value } \\
\end{array}$ \\
\hline & G & $T$ & & $0,15 / 0,11$ & 0,028 & 0,722 & $0,16 / 0,13$ & 0,469 & 1 & $0,12 / 0,12$ & 0,955 & 1 \\
\hline & G & C & & $0,35 / 0,36$ & 0,565 & 1 & $0,26 / 0,30$ & 0,285 & 1 & $0,3 / 0,31$ & 0,825 & 1 \\
\hline & A & $\mathrm{C}$ & & $0,52 / 0,55$ & 0,394 & 1 & $0,6 / 0,58$ & 0,637 & 1 & $0,58 / 0,57$ & 0,865 & 1 \\
\hline \multicolumn{4}{|c|}{ DYNLL1 (PIN); Chromosome 12: } & $\begin{array}{l}\text { Frequencies } \\
\text { Case/Control }\end{array}$ & $\begin{array}{l}\text { Nominal } \\
\text { P-Value } \\
\end{array}$ & $\begin{array}{c}\text { Bonferroni } \\
\text { P-Value }\end{array}$ & $\begin{array}{l}\text { Frequencies } \\
\text { Case/Control }\end{array}$ & $\begin{array}{l}\text { Nominal } \\
\text { P-Value } \\
\end{array}$ & $\begin{array}{c}\text { Bonferroni } \\
\text { P-Value }\end{array}$ & $\begin{array}{l}\text { Frequencies } \\
\text { Case/Control }\end{array}$ & $\begin{array}{c}\text { Nominal } \\
\text { P-Value } \\
\end{array}$ & $\begin{array}{c}\text { Bonferron } \\
\text { P-Value }\end{array}$ \\
\hline \multirow{4}{*}{ Block1: } & G & A & A & $0,29 / 0,31$ & 0,520 & 1 & $0,33 / 0,31$ & 0,684 & 1 & $0,28 / 0,24$ & 0,118 & 1 \\
\hline & G & $T$ & G & $0,36 / 0,34$ & 0,279 & 1 & $0,31 / 0,35$ & 0,363 & 1 & $0,4 / 0,38$ & 0,363 & 1 \\
\hline & $\mathrm{T}$ & A & G & $0,18 / 0,18$ & 0,859 & 1 & $0,21 / 0,20$ & 0,680 & 1 & $0,18 / 0,22$ & 0,102 & 1 \\
\hline & G & A & G & $0,18 / 0,19$ & 0,698 & 1 & $0,16 / 0,16$ & 0,837 & 1 & $0,13 / 0,16$ & 0,183 & 1 \\
\hline \multicolumn{4}{|c|}{ RASD1 (DEXRAS1); Chromosome 17: } & $\begin{array}{l}\text { Frequencies } \\
\text { Case/Control } \\
\end{array}$ & $\begin{array}{l}\text { Nominal } \\
\text { P-Value } \\
\end{array}$ & $\begin{array}{c}\text { Bonferroni } \\
\text { P-Value } \\
\end{array}$ & $\begin{array}{l}\text { Frequencies } \\
\text { Case/Control } \\
\end{array}$ & $\begin{array}{c}\text { Nominal } \\
\text { P-Value } \\
\end{array}$ & $\begin{array}{c}\text { Bonferroni } \\
\text { P-Value } \\
\end{array}$ & $\begin{array}{l}\text { Frequencies } \\
\text { Case/Control } \\
\end{array}$ & $\begin{array}{c}\text { Nominal } \\
\text { P-Value } \\
\end{array}$ & $\begin{array}{c}\text { Bonferron } \\
\text { P-Value } \\
\end{array}$ \\
\hline \multirow{3}{*}{ Block1: } & G & $C$ & & $0,24 / 0,27$ & 0,171 & 1 & $0,17 / 0,19$ & 0,640 & 1 & $0,29 / 0,25$ & 0,140 & 1 \\
\hline & G & G & & $0,03 / 0,02$ & 0,685 & 1 & - & -- & -- & $0,03 / 0,04$ & 0,305 & 1 \\
\hline & $\mathrm{C}$ & G & & $0,75 / 0,72$ & 0,222 & 1 & $0,84 / 0,82$ & 0,640 & 1 & $0,68 / 0,71$ & 0,306 & 1 \\
\hline
\end{tabular}


Table 3: Meta-analysis of 12 NOS1AP variants. Table shows all SNPs along with their minor/major alleles, cases and control counts for the genotypic and dominant model as well as the nominal $p$-values for each sample and the total sample. Further are given $p$-values for heterogeneity and odds ratios plus $p$-values of the fixed effect and random effect model. Bold indicates SNPs with at least one significant $p$-value $(p<0.05)$.

\begin{tabular}{|c|c|c|c|c|c|c|c|c|c|c|c|c|c|c|c|c|c|c|c|c|c|c|c|c|}
\hline \multirow{2}{*}{$\begin{array}{l}\text { SNPs } \\
\text { Alleles } \\
\text { (d/D) } \\
\text { Test } \\
\end{array}$} & \multicolumn{2}{|c|}{$\begin{array}{c}\text { rs1572495 } \\
\text { T/C }\end{array}$} & \multicolumn{2}{|c|}{$\begin{array}{c}\text { rs1538018 } \\
\text { C/G }\end{array}$} & \multicolumn{2}{|c|}{$\begin{array}{c}\text { rs945713 } \\
\text { C/T }\end{array}$} & \multicolumn{2}{|c|}{$\begin{array}{c}\text { rs1415263 } \\
\text { T/C }\end{array}$} & \multicolumn{2}{|c|}{$\begin{array}{c}\text { rs4306106 } \\
\text { A/G }\end{array}$} & \multicolumn{2}{|c|}{$\begin{array}{c}\text { rs3924139 } \\
\text { G/A }\end{array}$} & \multicolumn{2}{|c|}{$\begin{array}{c}\text { rs1508263 } \\
\text { A/G }\end{array}$} & \multicolumn{2}{|c|}{$\begin{array}{c}\text { rs3751284 } \\
\text { A/G }\end{array}$} & \multicolumn{2}{|c|}{$\begin{array}{c}\text { rs7521206 } \\
\text { G/C }\end{array}$} & \multicolumn{2}{|c|}{$\begin{array}{c}\text { rs } 905721 \\
\text { T/C }\end{array}$} & \multicolumn{2}{|c|}{$\begin{array}{c}\text { rs348624 } \\
\text { T/C }\end{array}$} & \multicolumn{2}{|c|}{$\begin{array}{c}\text { rs1964052 } \\
\text { T/C }\end{array}$} \\
\hline & $\mathrm{d} / \mathrm{D}$ & $d+/ d-$ & $d / D$ & $d+/ d-$ & $d / D$ & $d+/ d-$ & $d / D$ & $d+/ d-$ & $d / D$ & $d+/ d-$ & $d / D$ & $d+/ d-$ & $d / D$ & $d+/ d-$ & $d / D$ & $d+/ d-$ & $d / D$ & $d+/ d-$ & $\mathrm{d} / \mathrm{D}$ & $d+/ d-$ & $\mathrm{d} / \mathrm{D}$ & $d+/ d-$ & $d / D$ & $d+/ d-$ \\
\hline \multicolumn{25}{|c|}{ German sample (Controls: $n=720$; Cases: $n=270$ ) } \\
\hline Controls & $122 / 1282$ & 115/587 & -- & -- & $543 / 853$ & $441 / 257$ & $547 / 857$ & $440 / 262$ & $289 / 1101$ & $253 / 442$ & $493 / 901$ & $409 / 288$ & $636 / 756$ & $497 / 199$ & $487 / 903$ & $397 / 298$ & $505 / 899$ & $414 / 288$ & $510 / 886$ & $416 / 282$ & $161 / 1215$ & $151 / 537$ & $165 / 1235$ & $155 / 545$ \\
\hline Cases & $45 / 465$ & $42 / 213$ & -- & -- & $244 / 276$ & $187 / 73$ & $220 / 290$ & $177 / 78$ & $121 / 395$ & 107/151 & 202/316 & $162 / 97$ & 211/279 & $165 / 80$ & $174 / 336$ & $145 / 110$ & $183 / 327$ & $148 / 107$ & $192 / 324$ & $154 / 104$ & $57 / 439$ & $54 / 194$ & $61 / 445$ & $58 / 195$ \\
\hline \multicolumn{25}{|c|}{ Swedish sample (Controls: $n=168 ;$ Cases: $n=101$ ) } \\
\hline Controls & $24 / 302$ & $23 / 140$ & $73 / 237$ & $65 / 90$ & $143 / 169$ & $107 / 49$ & $155 / 167$ & $117 / 44$ & $96 / 214$ & $80 / 75$ & $145 / 169$ & $112 / 45$ & $136 / 170$ & $102 / 51$ & $125 / 199$ & $95 / 67$ & $125 / 203$ & $105 / 59$ & 116/198 & $98 / 59$ & $27 / 293$ & $25 / 135$ & 29/297 & $27 / 136$ \\
\hline Cases & $11 / 189$ & $11 / 89$ & $51 / 143$ & $43 / 54$ & $72 / 122$ & $60 / 37$ & $71 / 127$ & $61 / 38$ & $41 / 153$ & $38 / 59$ & $63 / 131$ & $56 / 41$ & 99/91 & $74 / 21$ & $70 / 130$ & $62 / 38$ & $79 / 121$ & $66 / 34$ & $77 / 117$ & $64 / 33$ & $21 / 171$ & $20 / 76$ & $21 / 177$ & $20 / 79$ \\
\hline$P$-value & 0,474 & 0,571 & 0,524 & 0,794 & 0,064 & 0,278 & 0,006 & 0,074 & 0,018 & 0,069 & 0,003 & 0,029 & 0,116 & 0,063 & 0,457 & 0,606 & 0,783 & 0,791 & 0,573 & 0,593 & 0,352 & 0,312 & 0,542 & 0,508 \\
\hline \multicolumn{25}{|c|}{ Spanish sample (Controls: $n=360 ;$ Cases: $n=270$ ) } \\
\hline Controls & $60 / 624$ & $58 / 284$ & -- & -- & 288/398 & $225 / 118$ & $304 / 378$ & $233 / 108$ & $197 / 489$ & $168 / 175$ & $284 / 406$ & $219 / 126$ & $314 / 370$ & $245 / 97$ & $232 / 440$ & $200 / 136$ & $266 / 418$ & 219/123 & $269 / 415$ & 220/122 & -- & -- & $74 / 606$ & $72 / 268$ \\
\hline Cases & $49 / 487$ & $45 / 223$ & -- & -- & $237 / 297$ & $188 / 79$ & $238 / 292$ & $188 / 77$ & $150 / 382$ & $134 / 132$ & $221 / 313$ & $180 / 87$ & $202 / 330$ & $172 / 94$ & $177 / 357$ & $144 / 123$ & $196 / 340$ & $162 / 106$ & $196 / 340$ & $163 / 105$ & -- & - & $63 / 459$ & $58 / 203$ \\
\hline \multicolumn{25}{|c|}{ Nicodemus et al., 2010 (Controls: n=487; Cases: n=415) } \\
\hline Controls & $94 / 646$ & $81 / 288$ & $140 / 476$ & $126 / 182$ & 296/422 & $243 / 116$ & $309 / 429$ & $248 / 121$ & -- & -- & -- & -- & -- & - & $263 / 469$ & 214/152 & - & - & - & -- & $106 / 516$ & $92 / 219$ & -- & - \\
\hline Cases & $55 / 585$ & $53 / 267$ & $152 / 392$ & $132 / 140$ & 238/394 & $193 / 123$ & 242/388 & $201 / 114$ & -- & -- & - & -- & -- & -- & $234 / 400$ & $202 / 115$ & -- & -- & -- & -- & $67 / 485$ & $62 / 214$ & -- & -- \\
\hline$P$-value & 0,014 & 0.075 & 0,041 & 0.065 & 0,181 & 0,073 & 0,194 & 0,351 & -- & -- & -- & -- & -- & -- & 0,707 & 0,161 & -- & - & -- & -- & 0,018 & 0,050 & -- & -- \\
\hline \multicolumn{25}{|c|}{ Delorme et al., 2010 (Controls: n=286; Cases: n=296) } \\
\hline Controls & -- & -- & -- & -- & -- & -- & -- & -- & -- & -- & - & -- & -- & - & $61 / 91$ & $50 / 26$ & - & - & $189 / 309$ & $147 / 102$ & $34 / 283$ & $31 / 128$ & $34 / 283$ & $31 / 128$ \\
\hline Cases & -- & -- & -- & - & - & - & -- & - & -- & -- & - & - & -- & - & $30 / 58$ & $24 / 20$ & -- & -- & $213 / 353$ & $169 / 114$ & $74 / 500$ & 69/218 & $74 / 500$ & $69 / 218$ \\
\hline$P$-value & .- & .- & -- & -- & -- & -- & .- & -- & -- & .- & -- & -- & .- & -- & 0,353 & 0,222 & -- & .- & 0,914 & 0,873 & 0,343 & 0,270 & 0,343 & 0,270 \\
\hline
\end{tabular}

Puri et al., 2005 (Controls: $n=450$; Cases: $n=450$ )

Controls $\quad 81 / 797 \quad--\quad 207 / 631 \quad-\quad 321 / 539 \quad-\quad-331 / 549$

$\begin{array}{lllllllll}\text { Cases } & 65 / 715 & - & 182 / 598 & - & 294 / 486 & - & 270 / 502\end{array}$ 


\begin{tabular}{|c|c|c|c|c|c|c|c|c|c|c|c|c|c|c|c|c|c|c|c|c|c|c|c|c|}
\hline$P$-value & 0,522 & -- & 0,520 & -- & 0,878 & -- & 0,266 & - & -- & -- & - & - & - & - & -- & -- & - & - & - & - & - & - & - & - \\
\hline \multicolumn{25}{|c|}{ Zheng et al., 2005 (Controls: n=941; Cases: $n=664$ ) } \\
\hline Controls & $359 / 1523$ & $324 / 617$ & - & - & $1354 / 528$ & $868 / 73$ & $882 / 1000$ & $660 / 274$ & -- & -- & - & -- & -- & - & $1115 / 767$ & $776 / 165$ & - & - & $961 / 921$ & $716 / 225$ & $346 / 1536$ & $319 / 622$ & -- & - \\
\hline Cases & $253 / 1075$ & $228 / 436$ & - & - & $959 / 369$ & $609 / 55$ & $660 / 668$ & $489 / 175$ & -- & -- & - & - & -- & - & $784 / 544$ & $544 / 120$ & - & -- & $700 / 628$ & $521 / 143$ & $169 / 1159$ & $155 / 509$ & -- & - \\
\hline$P$-value & 0,990 & 0,969 & -- & - & 0,870 & 0,702 & 0,114 & 0,191 & $\ldots$ & -- & -- & -- & .- & - & 0,905 & 0,781 & - & - & 0,357 & 0,265 & $2 * 10^{-5}$ & $5^{*} 10^{-6}$ & - & - \\
\hline \multicolumn{25}{|c|}{ Total (Controls: $n=3412 ;$ Cases: $n=2406$ ) } \\
\hline Controls & $740 / 5174$ & $601 / 1916$ & $420 / 1344$ & $191 / 272$ & $2945 / 2909$ & $1884 / 613$ & $2528 / 3380$ & $1698 / 809$ & $582 / 1804$ & $501 / 692$ & $922 / 1476$ & $740 / 459$ & 1086/1296 & $844 / 347$ & $2283 / 2869$ & $1732 / 844$ & $896 / 1520$ & $738 / 470$ & $2045 / 2729$ & $1597 / 790$ & $674 / 3843$ & $618 / 1641$ & $302 / 2421$ & $285 / 1077$ \\
\hline Cases & $478 / 3516$ & $379 / 1228$ & $385 / 1133$ & $175 / 194$ & 2044/1944 & $1237 / 367$ & $1701 / 2267$ & $1116 / 482$ & $312 / 930$ & $279 / 342$ & $486 / 760$ & $398 / 225$ & $512 / 700$ & $411 / 195$ & $1469 / 1825$ & $1121 / 526$ & $458 / 788$ & $376 / 247$ & $1378 / 1762$ & $1071 / 499$ & $388 / 2754$ & $360 / 1211$ & $219 / 1581$ & $205 / 695$ \\
\hline \multicolumn{25}{|c|}{ Heterogeneity: } \\
\hline P-value & 0.301 & -- & 0.138 & - & 0.008 & -- & 0.008 & -- & 0.026 & 0.06 & 0.003 & 0.033 & 0.015 & 0.035 & 0.891 & 0.340 & 0.732 & 0.731 & 0.270 & 0.712 & 0.009 & 0.004 & 0.906 & 0.854 \\
\hline \multicolumn{25}{|c|}{ Cochran-Mantel-Haenszel Metaanalysis: } \\
\hline $\begin{array}{l}\text { Fixed } \\
\text { effect }\end{array}$ & 0,91 & -- & 1,09 & - & 1,04 & -- & 1,00 & -- & 0,98 & 1,04 & 0,99 & 1,06 & 0.88 & 0.87 & 0,97 & 0,99 & 0,97 & 0,94 & 1,09 & 1,04 & 0,78 & 0,77 & 1,12 & 1,12 \\
\hline$P$-value & 0.142 & - & 0.316 & - & 0.426 & - & 0.983 & - & 0.819 & 0.706 & 0.911 & 0,877 & 0.086 & 0.237 & 0.541 & 0.858 & 0.710 & 0.579 & 0.064 & 0.633 & 0.0004 & 0.001 & 0.295 & 0.307 \\
\hline \multicolumn{25}{|c|}{ DerSimonian and Laird Metaanalysis: } \\
\hline $\begin{array}{l}\text { Random } \\
\text { effect }\end{array}$ & 0,90 & -- & 1,11 & -- & 1,23 & -- & 1,04 & -- & 0,92 & 0.98 & 0.90 & 0,97 & 0,93 & 0.95 & 0,97 & 0,98 & 0,97 & 0,94 & 1,10 & 1,04 & 0,88 & 0,89 & 1,11 & 1,12 \\
\hline$P$-value & 0.144 & $\ldots$ & 0.397 & -- & 0.836 & - & 0.596 & - & 0.599 & 0.903 & 0,565 & 0,877 & 0.648 & 0.812 & 0.527 & 0.830 & 0.684 & 0.543 & 0.098 & 0.611 & 0.366 & 0,502 & 0.275 & 0.285 \\
\hline
\end{tabular}

${ }^{*}$ significant after Bonferroni correction $(\mathrm{p}<0.05)$ 
Table 4: Meta-analysis of 7 NOS1 variants. Table shows all SNPs along with their minor/major alleles, cases and control counts for the genotypic and dominant model as well as the nominal $p$-values for each sample and the total sample. Further are given $p$-values for heterogeneity and odds ratios plus $p$-values of the fixed effect and random effect model. Bold indicates SNPs with at least one significant $p$-value $(p<0.05)$.

\begin{tabular}{|c|c|c|c|c|c|c|c|c|c|c|c|c|c|c|}
\hline \multirow{3}{*}{$\begin{array}{l}\text { SNPs } \\
\text { Alleles (d/D) } \\
\text { Test }\end{array}$} & \multirow{2}{*}{\multicolumn{2}{|c|}{$\begin{array}{c}\text { rs3782206 } \\
\text { T/C }\end{array}$}} & \multirow{2}{*}{\multicolumn{2}{|c|}{$\begin{array}{c}\text { rs } 499776 \\
\text { A/G }\end{array}$}} & \multirow{2}{*}{\multicolumn{2}{|c|}{$\begin{array}{c}\text { rs3782219 } \\
\text { T/C }\end{array}$}} & \multirow{2}{*}{\multicolumn{2}{|c|}{$\begin{array}{c}\text { rs3782221 } \\
\text { A/G }\end{array}$}} & \multirow{2}{*}{\multicolumn{2}{|c|}{$\begin{array}{c}\text { rs } 1879417 \\
\text { T/C }\end{array}$}} & \multirow{2}{*}{\multicolumn{2}{|c|}{$\begin{array}{c}\text { rs } 4767540 \\
\text { G/A }\end{array}$}} & \multirow{2}{*}{\multicolumn{2}{|c|}{$\begin{array}{c}\text { rs } 41279104 \\
\text { T/C }\end{array}$}} \\
\hline & & & & & & & & & & & & & & \\
\hline & $d / D$ & $d+/ d-$ & $d / D$ & $d+/ d-$ & $d / D$ & $d+/ d-$ & $d / D$ & $d+/ d-$ & $d / D$ & $d+/ d-$ & $d / D$ & $d+/ d-$ & $\mathrm{d} / \mathrm{D}$ & $d+/ d-$ \\
\hline \multicolumn{15}{|c|}{ German sample (Controls: $n=720 ;$ Cases: $n=270$ ) } \\
\hline Controls & $155 / 1237$ & $148 / 548$ & $577 / 817$ & $454 / 243$ & -- & -- & $306 / 1084$ & $275 / 420$ & $675 / 705$ & $512 / 178$ & $644 / 750$ & $484 / 213$ & $146 / 1248$ & $138 / 559$ \\
\hline Cases & $54 / 464$ & $53 / 206$ & 209/309 & $177 / 82$ & -- & -- & $119 / 385$ & 106/146 & $260 / 244$ & $195 / 57$ & $250 / 264$ & $186 / 71$ & $70 / 434$ & $68 / 184$ \\
\hline$P$-value & 0,681 & 0,858 & 0,714 & 0,398 & -- & -- & 0,455 & 0,500 & 0,323 & 0,350 & 0,352 & 0,425 & 0,041 & 0,020 \\
\hline \multicolumn{15}{|c|}{ Swedish sample (Controls: $n=168 ;$ Cases: $n=101$ ) } \\
\hline Controls & $34 / 282$ & $32 / 126$ & $114 / 200$ & 102/55 & $63 / 255$ & $59 / 100$ & $72 / 246$ & $67 / 92$ & 143/181 & $117 / 45$ & 132/178 & 104/51 & $41 / 283$ & $38 / 124$ \\
\hline Cases & $25 / 169$ & $21 / 76$ & $77 / 117$ & $57 / 40$ & $35 / 159$ & $29 / 68$ & $40 / 160$ & $33 / 67$ & $99 / 99$ & $71 / 28$ & $76 / 114$ & $59 / 36$ & $28 / 168$ & $26 / 72$ \\
\hline$P$-value & 0,478 & 0,874 & 0,452 & 0,351 & 0,645 & 0,278 & 0,512 & 0,151 & 0,206 & 1,000 & 0,577 & 0,494 & 0,596 & 0,656 \\
\hline \multicolumn{15}{|c|}{ Spanish sample (Controls: $n=360$; Cases: $n=270$ ) } \\
\hline Controls & $76 / 608$ & $74 / 268$ & $282 / 404$ & $224 / 119$ & - & -- & $161 / 519$ & $144 / 196$ & $313 / 363$ & $241 / 97$ & $294 / 396$ & $227 / 118$ & $82 / 600$ & $73 / 268$ \\
\hline Cases & $70 / 464$ & $68 / 199$ & $189 / 347$ & $155 / 113$ & -- & -- & $141 / 383$ & $118 / 144$ & $234 / 300$ & $183 / 84$ & $223 / 307$ & $176 / 89$ & $63 / 473$ & $59 / 209$ \\
\hline$P$-value & 0,288 & 0,289 & 0,038 & 0,065 & -- & -- & 0,203 & 0,562 & 0,416 & 0,475 & 0,861 & 0,931 & 0,929 & 0,921 \\
\hline \multicolumn{15}{|c|}{ Cui et al., 2010 (Controls: n=377; Cases: n=343) } \\
\hline Controls & $197 / 557$ & $164 / 213$ & -- & - & $302 / 448$ & $247 / 128$ & $347 / 403$ & 270/105 & -- & -- & -- & -- & $132 / 622$ & $119 / 258$ \\
\hline Cases & $161 / 525$ & 146/197 & -- & - & $289 / 397$ & $236 / 107$ & $303 / 383$ & $232 / 111$ & -- & -- & -- & -- & $168 / 518$ & $147 / 196$ \\
\hline$P$-value & 0,244 & 0,800 & -- & -- & 0,474 & 0,402 & 0,425 & 0,203 & -- & -- & -- & -- & 0,001 & 0,002 \\
\hline \multicolumn{15}{|c|}{ Okumura et al., 2009 (Controls: $n=519$; Cases: $n=542$ ) } \\
\hline Controls & $641 / 1879$ & $554 / 706$ & -- & -- & $1121 / 1399$ & $866 / 394$ & $441 / 597$ & $344 / 175$ & -- & -- & -- & -- & $182 / 856$ & $165 / 354$ \\
\hline Cases & $645 / 1663$ & $544 / 610$ & -- & - & $950 / 1358$ & $745 / 409$ & $486 / 598$ & $369 / 173$ & -- & -- & -- & -- & $212 / 872$ & $187 / 355$ \\
\hline$P$-value & 0,049 & 0,118 & -- & -- & 0,020 & 0,030 & 0,276 & 0,532 & -- & -- & -- & -- & 0,231 & 0,349 \\
\hline
\end{tabular}

Tang et al., 2008 (Controls: $n=480 ;$ Cases: $n=480$ ) 


\begin{tabular}{lcccccccccccccc} 
Controls & $218 / 718$ & $186 / 282$ & $204 / 742$ & $185 / 288$ & $404 / 540$ & $315 / 157$ & $458 / 428$ & $332 / 111$ & $498 / 430$ & $366 / 98$ & $185 / 751$ & $168 / 300$ & -- & -- \\
Cases & $266 / 676$ & $221 / 250$ & $162 / 784$ & $152 / 321$ & $409 / 525$ & $319 / 148$ & $493 / 407$ & $355 / 85$ & $497 / 449$ & $365 / 108$ & $188 / 740$ & $168 / 296$ & -- & -- \\
$P$ P-value & 0,014 & 0,026 & 0,015 & 0,025 & 0,664 & 0,607 & 0,191 & 0,040 & 0,625 & 0,527 & 0,790 & 0,922 & -- & -- \\
\hline \hline
\end{tabular}

Total (Controls: $n=2624$; Cases: $n=2006$ )

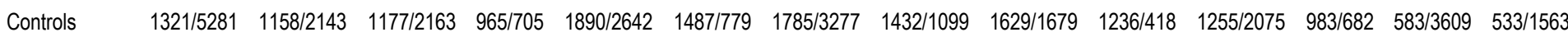

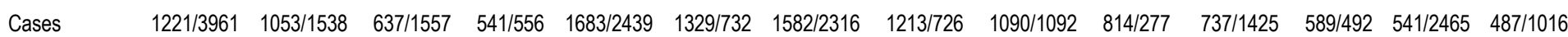
Heterogeneity:

\begin{tabular}{lcccccccccccccc} 
P-value & 0.166 & 0.557 & 0.139 & 0.114 & 0.209 & 0.151 & 0.524 & 0.128 & 0.299 & 0.597 & 0.764 & 0.722 & 0.245 & 0.256 \\
Cochran-Mantel-Haenszel Metaanalysis: & & & & & & & & & & & \\
Fixed effect & 1,11 & 1,13 & 0,86 & 0.84 & 0.94 & 0.92 & 1,07 & 1,07 & 1,01 & 0.98 & 1,03 & 1,03 & 1,25 & 1,29 \\
$\begin{array}{l}P \text {-value } \\
\text { DerSimonian and Laird Metaanalysis: }\end{array}$ & 0.024 & 0.030 & 0.020 & 0.039 & 0.182 & 0.195 & 0.161 & 0.425 & 0.826 & 0.849 & 0.700 & 0.754 & 0.001 & 0.001 \\
Random effect & 1,10 & 1,13 & 0,87 & 0.84 & 0.96 & 0.94 & 1,07 & 1,07 & 1,02 & 0.98 & 1,03 & 1,03 & 1,25 & 1,29 \\
$P$-value & 0.152 & 0.028 & 0.112 & 0.147 & 0.524 & 0.542 & 0.157 & 0.153 & 0.781 & 0.802 & 0.677 & 0.727 & 0.006 & 0.005 \\
\hline
\end{tabular}



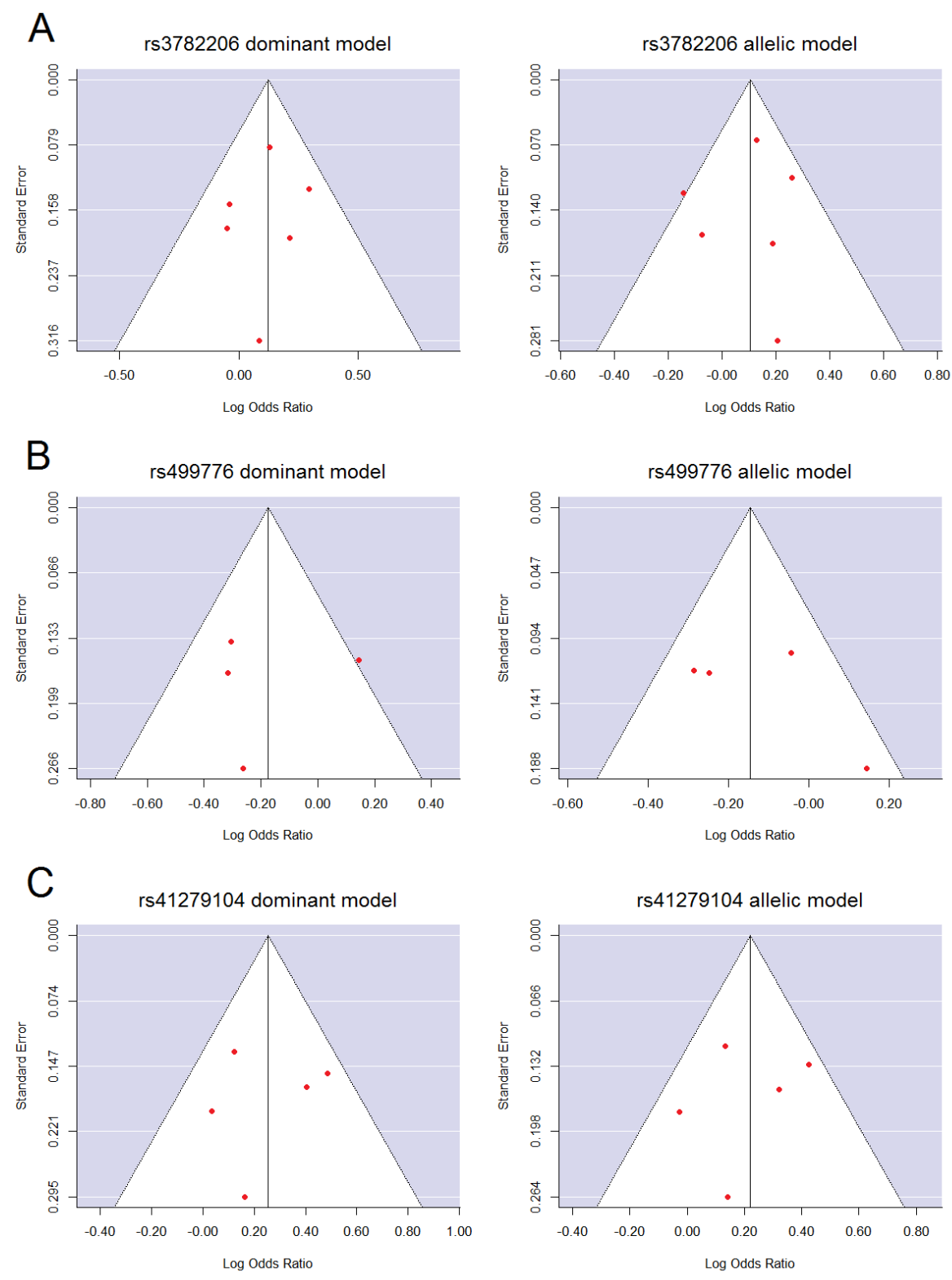
Supplementary Figure 1: Funnel plots of NOS1AP rs3782206 dominant and allelic model (A), NOS1 rs499776 dominant and allelic model (B) and NOS1 rs41279104 dominant and allelic model (C).

Supplementary Table 1: Primer sequences in 5'-3' direction used for Sequenom's MassArray ${ }^{\circledR}$ system.

\begin{tabular}{|c|c|c|c|}
\hline SNP ID & Primary PCR Primer 1 & Primary PCR Primer 2 & Extend Primer \\
\hline rs12857 & ACGTTGGATGCTTAGATGCGCCACGGTTTC & ACGTTGGATGGGTGCTAGCACAGCTCAGG & tTTTCGGTAGCGACGGTA \\
\hline rs3916065 & ACGTTGGATGAAAGCGCCACCTAGCAACG & ACGTTGGATGCAGGAACCACACAGAAGGG & ggaacCGGTATCTAAGATCAGGGAGC \\
\hline rs787828 & ACGTTGGATGGCAGTCACCTAGCTGCTTAG & ACGTTGGATGGGTCCTGACTTGTAGTTAGC & tttccCCTAGCTGCTTAGAAATCCC \\
\hline rs1415263 & ACGTTGGATGCTAAATGGTGAGCCCCAATG & ACGTTGGATGTGGGTTGGAAGGCAACATAC & accTTAGGCATTCCCAATTCCTTTATC \\
\hline rs4145621 & ACGTTGGATGCCATCACCCCTTGATAAAAG & ACGTTGGATGGACTTAAATCCAACTCTTC & TGCTGTGGTTTGATGGAGAA \\
\hline rs348624 & ACGTTGGATGCCTTGTTCTGCAGCAAAAGC & ACGTTGGATGACCAGTTGGCTGCTGAGG & gctgaAGCAAAAGCTGATGCAC \\
\hline rs9788155 & ACGTTGGATGGACAGATCATCCGTTCTGAG & ACGTTGGATGTGAAGCCCACAGGGAATTTG & GTTCTGAGTAGGGCTTAA \\
\hline rs 1572495 & ACGTTGGATGCTTCAGAGGATGCAGATTTG & ACGTTGGATGCCCTGCCTAAATATCCTTTG & ATGCAGATTTGAGCTGAGCC \\
\hline rs 1538018 & ACGTTGGATGCCAACTCTGAACTTAGGATG & ACGTTGGATGACTTTCTCCCTAAGTGGCCC & GGATGAAAAGGAGAACAATGA \\
\hline rs945713 & ACGTTGGATGCTGTGTGACACTCCCATTTG & ACGTTGGATGGATAACTTCAGTTTTTTGAC & TCCCATTTGGATATCCCAAAG \\
\hline rs 3751284 & ACGTTGGATGTGCAGATGGCCAGGAAGATG & ACGTTGGATGACAGAAGCCGCAGTGCCTAC & CAGGAAGATGGAGAGAG \\
\hline rs905721 & ACGTTGGATGCCTCCTCTGGAATGATAAGC & ACGTTGGATGATGCCCTCCACATTCAGTTC & cCTGATAAGCCCAGATGCC \\
\hline rs 1964052 & ACGTTGGATGCTGGAATATAGGGGTAGGTC & ACGTTGGATGAAGGCTCTGGAAAGAGTGTC & CAGAAAGCACCACCAAAAACTTA \\
\hline rs 4306106 & ACGTTGGATGTATCGCTTTCAGGGTCAAGG & ACGTTGGATGGAAGAAGAAGAATGAATTTC & ctcaCAAAACTCAGTAAAGCTACCC \\
\hline rs 3924139 & ACGTTGGATGCAGTGTTGTATACAATGCGG & ACGTTGGATGAACAACTGCCTGTGCTCAAG & aaAATGCGGTATATAATATCTAACA \\
\hline rs 1508263 & ACGTTGGATGGGGACAGCCGTTTAGTTAC & ACGTTGGATGTGATCTCACTATTAAGTTG & agggcGTTACTTGGTAGTGAAAGAAA \\
\hline rs7521206 & ACGTTGGATGGCCGTAGTGTCACATCACTC & ACGTTGGATGCTGTGTTGTCTTTGGCAATG & cacgCTGTGCCACATCACTGA \\
\hline rs 4924755 & ACGTTGGATGCAGAGAGATTGGTGTTCTGG & ACGTTGGATGTGTAGAGCCCCATCCCCCTT & ttTGCCTTAGCCATGAGAC \\
\hline rs711352 & ACGTTGGATGGACACGAACAAAACCTTACC & ACGTTGGATGAAACCAAATAAAGCAATAAC & cccctGTGTTTATACTGTGTGTGT \\
\hline rs2232841 & ACGTTGGATGGTTAAGTCAAATCCAACGGC & ACGTTGGATGGATCGCCGGGAGGGGAGAC & AATCCAACGGCCCGGTGCGCCCC \\
\hline rs2232838 & ACGTTGGATGGCCAAAGGCAGAGCAAGCG & ACGTTGGATGCTCGGGCTAGGCTGGGCT & gttTGCCCAGATCCTGGGAG \\
\hline rs 4767540 & ACGTTGGATGGCTTTAGGGTTTCCACTCTG & ACGTTGGATGAGGCTTAGAGTCCCAGACAG & TTCСАСТCTGСССТСАТ \\
\hline rs1879417 & ACGTTGGATGCTCTACTCGGCCTTCAAGTC & ACGTTGGATGGAAGAGGGACATGCAGAGTG & GCCTTCAAGTCTTAGCG \\
\hline rs3782221 & ACGTTGGATGCTTAACCACATTCCAAGCCC & ACGTTGGATGGGGTGTCTTATGACAAGACT & cCaCGCACAGACCCACAGAACCTGAGT \\
\hline rs3782219 & ACGTTGGATGTCCAGGGCATTGCAACTTAG & ACGTTGGATGCACCTCCTCAATTAACTGGG & tgcacCTTAGCCTGCAAATTGTAG \\
\hline rs499776 & ACGTTGGATGCTACATACCTGCCCCATTGC & ACGTTGGATGCAAACCCTGGTTTTTCTAGC & GCCCCATTGCTGTAAAT \\
\hline rs3837437 & ACGTTGGATGTGAAGAATGTTGTTAGGTGC & ACGTTGGATGCTGGGTGACAGAGCAAGAAC & ggaAATGTTGTTAGGTGCTTTTTTT \\
\hline
\end{tabular}


rs3782206 ACGTTGGATGCTACACACACAAAAGTCTTTC rs598747 ACGTTGGATGCATGAAGAAGATTTGGCACC rs598704 ACGTTGGATGTGAGTTGCGTGTGGCCCCG rs308969 ACGTTGGATGGCTAATGGACCTGAAAGAGC rs931676 ACGTTGGATGCACTTTCCACCCATGGCTTG rs3817004 ACGTTGGATGTCCCAGCCAAAGTGTAAGTA rs35528972 ACGTTGGATGTGCTAGGCATGGAGGTACAG rs3755724 ACGTTGGATGTTGGAGCCTCATAAATAGGG rs41279104 ACGTTGGATGAAGGCTTGGCCTCCCAACC
ACGTTGGATGAGTAAGGAAGGCTGGGTAAC ACGTTGGATGTCAGCAGCACCAGGTGCTC

ACGTTGGATGTCTTCTCTCTGTTGGCCTTG

ACGTTGGATGCTAGCCTGAGATTTGATCCT ACGTTGGATGTTGCAGTATGCAGGCCTCC

ACGTTGGATGCTGCACTGTATGAAGTTGGG

ACGTTGGATGCACCCTCAGTTAGACTTGAC

ACGTTGGATGGAATGAGACGAGCTACTCAG ACGTTGGATGTTTAATTGACACCAGGTGGC
ccctgTAAATATGCAACTAAATGTCCT CtIGCACCACACCTTCTACA

AGGAGCACCTGGTGCTGCTGAC CCCCTAGAGTATAAATCCTCCCA GGCTTGTCACAGAAGTT

CAGCCAAAGTGTAAGTACTTTGAG ctaatGGGAAATGAGGAAACATG cccagCTCATAAATAGGGCATTGAAA CCCCCTCCCAACCCAGCAGAGCC 
Supplementary Table 2: Functional prediction of $r s 945713$, rs3782206, rs499776 and rs41279104 (in bold and highlighted grey) and their proxy SNPs in high linkage disequilibrium $\left(r^{2} \geq 0.8\right.$ and $\left.D^{\prime}=1\right)$. All Transcription Factors (TFs), shown in table have a core similarity of 1 and a matrix similarity of 0.85 and more. Changes in Splicing Regulatory Elements (SREs), like Splicing Enhancers (Srp40, SF2/ASF, SC35, SRp55, 9G8, Tra-B) and Splicing Inhibitors (hnRNP A1) with a match similarity of at least 65.0 are shown for minor and major alleles.

\begin{tabular}{|c|c|c|c|c|c|c|}
\hline \multirow{2}{*}{$\begin{array}{l}\text { Associated } \\
\text { SNP }\end{array}$} & \multirow[t]{2}{*}{ Proxy SNP } & \multirow{2}{*}{$\begin{array}{l}\text { Position } \\
\text { (bp) }\end{array}$} & \multirow{2}{*}{$\begin{array}{l}\text { Alleles } \\
\text { (d/D) }\end{array}$} & \multirow[t]{2}{*}{ location } & \multicolumn{2}{|c|}{ Transcription Factor (TF) } \\
\hline & & & & & Minor Allele (d) & Major Allele (D) \\
\hline \multicolumn{7}{|c|}{ NOS1AP; chromosome 1} \\
\hline rs945713 & rs10918796 & 162133343 & $\mathrm{C} / \mathrm{A}$ & Intron & SF2/ASF & 9G8,hnRNP A1 \\
\hline rs945713 & rs10918797 & 162133602 & $A / G$ & Intron & $9 \mathrm{G} 8$ & SF2/ASF \\
\hline rs945713 & rs6427656 & 162134638 & $\mathrm{G} / \mathrm{A}$ & Intron & - & - \\
\hline rs945713 & rs945713 & 162135670 & G/A & Intron & hnRNP A1 & $9 \mathrm{G} 8$, Tra2- $\beta$ \\
\hline rs945713 & rs11581189 & 162136904 & $\mathrm{C} / \mathrm{T}$ & Intron & SRp55 & SC35 \\
\hline rs945713 & rs11805598 & 162140336 & $A / G$ & Intron & $\begin{array}{c}\text { 9G8,Tra2- } \beta, \text { hnRNP } \\
\text { A1 }\end{array}$ & - \\
\hline rs945713 & rs7549718 & 162140862 & $\mathrm{~A} / \mathrm{G}$ & Intron & Tra2- $\beta, 9 G 8$ & - \\
\hline \multicolumn{7}{|c|}{ NOS1; chromosome 12} \\
\hline rs3782206 & rs7961147 & 117738879 & $\mathrm{~T} / \mathrm{C}$ & Intron & Tra2- $\beta$ & \\
\hline rs3782206 & rs12578810 & 117738948 & $\mathrm{~T} / \mathrm{C}$ & Intron & Tra2- $\beta$ & $\begin{array}{c}\text { SF2/ASF, } 9 G 8, \text { hnRNP } \\
\text { A1 }\end{array}$ \\
\hline rs3782206 & rs12810591 & 117739450 & $\mathrm{C} / \mathrm{T}$ & Intron & - & SRp40,hnRNP A1 \\
\hline rs3782206 & rs12811583 & 117739942 & $\mathrm{C} / \mathrm{T}$ & Intron & - & SRp55 \\
\hline rs3782206 & rs3825103 & 117740509 & $\mathrm{C} / \mathrm{T}$ & Intron & - & 9G8, hnRNP A1 \\
\hline rs3782206 & rs12811676 & 117741229 & $A / G$ & Intron & - & SRp40, SC35, SF2/ASF \\
\hline rs3782206 & rs12812274 & 117742714 & $A / G$ & Intron & - & - \\
\hline rs3782206 & rs6490124 & 117743269 & $C / A$ & Intron & $9 \mathrm{G} 8$ & - \\
\hline rs3782206 & rs7139134 & 117743766 & $\mathrm{~T} / \mathrm{C}$ & Intron & Tra2- $\beta$ & hnRNP A1 \\
\hline rs3782206 & rs11068444 & 117744743 & $\mathrm{G} / \mathrm{A}$ & Intron & SRp55 & hnRNP A1 \\
\hline rs3782206 & rs11068445 & 117744929 & $A / G$ & Intron & hnRNP A1 & SRp40 \\
\hline rs3782206 & rs3782206 & 117745089 & $\mathrm{~T} / \mathrm{C}$ & Intron & - & - \\
\hline rs3782206 & rs35555584 & 117746177 & $C / A$ & Intron & SF2/ASF & SC35, hnRNP A1 \\
\hline rs3782206 & rs7310618 & 117747306 & $\mathrm{G} / \mathrm{C}$ & Intron & SRp55 & - \\
\hline
\end{tabular}




\begin{tabular}{|cccclcc|} 
rs3782206 & rs7299154 & 117747395 & G/T & Intron & - & SF2/ASF \\
rs3782206 & rs10850809 & 117747441 & C/G & Intron & hnRNP A1 & SF2/ASF \\
rs3782206 & rs11068447 & 117747687 & T/C & Intron & $9 G 8$ & SC35 \\
rs3782206 & rs35736046 & 117747885 & G/T & Intron & - & Tra2- $\beta$ \\
rs3782206 & rs12824048 & 117748042 & T/C & Intron & 9 G8 & - \\
rs3782206 & rs36020061 & 117748156 & C/G & Intron & SRp55 & - \\
rs3782206 & rs9658309 & 117748304 & T/A & Intron & - & - \\
rs3782206 & rs9658308 & 117748410 & G/A & Intron & - & - \\
rs3782206 & rs9658297 & 117750695 & T/C & Intron & hnRNP A1 & 9G8 \\
rs3782206 & rs35320403 & 117752761 & C/G & Intron & SRp55 & SRp40 \\
\hline rs499776 & rs816293 & 117762699 & G/C & Intron & - & - \\
rs499776 & rs570234 & 117770982 & G/T & Intron & - & Tra2- $\beta$ \\
rs499776 & rs576881 & 117772835 & G/A & Intron & - & - \\
rs499776 & rs1681506 & 117775578 & C/T & Intron & - & SRp40 \\
rs499776 & rs499776 & $\mathbf{1 1 7 7 7 9 4 9 9}$ & A/G & Intron & - & SRp55 \\
\hline rs41279104 & rs900622 & 117875158 & C/T & Upstream & E2F & - \\
rs41279104 & rs900623 & 117875160 & T/G & Upstream & - & - \\
rs41279104 & rs41279104 & $\mathbf{1 1 7 8 7 7 4 8 5}$ & T/C & Upstream & - & - \\
rs41279104 & rs12316771 & 117879236 & C/T & Upstream & - & HOXC9,MSX1,ELF5,DLX1 \\
rs41279104 & rs34731287 & 117880958 & A/C & Upstream & - & SPZ1,MAZR \\
rs41279104 & rs12312120 & 117881133 & T/C & Upstream & HMX3 & - \\
rs41279104 & rs17618096 & 117882250 & C/G & Upstream & - & - \\
\hline
\end{tabular}

